\title{
Advanced imaging for detection and differentiation of colorectal neoplasia: European Society of Gastrointestinal Endoscopy (ESGE) Guideline
}

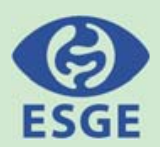

Authors

Institutions
Michał F. Kamiński ${ }^{1}$, Cesare Hassan², Raf Bisschops ${ }^{3}$, Jürgen Pohl ${ }^{4}$, Maria Pellisé ${ }^{5}$, Evelien Dekker ${ }^{6}$, Ana Ignjatovic-Wilson ${ }^{7}$, Arthur Hoffman ${ }^{8}$, Gaius Longcroft-Wheaton ${ }^{9}$, Denis Heresbach ${ }^{10}$, Jean-Marc Dumonceau ${ }^{11}$, James E. East ${ }^{12}$

Institutions are listed at the end of article.
Bibliography

DOI http://dx.doi.org/

10.1055/s-0034-1365348

Published online: 17.3.2014

Endoscopy 2014; 46: 435-449

(c) Georg Thieme Verlag KG

Stuttgart · New York

ISSN 0013-726X

\section{Corresponding author}

Michał F. Kamiński, MD PhD

Department of

Gastroenterological Oncology

Institute of Oncology

Roentgen Street 5

Warsaw

Poland

Fax: +48 225463057

mfkaminski@coi.waw.pl

This Guideline is an official statement of the European Society of Gastrointestinal Endoscopy (ESGE). It addresses the role of advanced endoscopic imaging for the detection and differentiation of colorectal neoplasia.

\section{Main recommendations}

1 ESGE suggests the routine use of high definition white-light endoscopy systems for detecting colorectal neoplasia in average risk populations (weak recommendation, moderate quality evidence).

2 ESGE recommends the routine use of high definition systems and pancolonic conventional or virtual (narrow band imaging [NBI], i-SCAN) chromoendoscopy in patients with known or suspected Lynch syndrome (strong recommendation, low quality evidence).

2b ESGE recommends the routine use of high definition systems and pancolonic conventional or virtual (NBI) chromoendoscopy in patients with known or suspected serrated polyposis syndrome (strong recommendation, low quality evidence).

3 ESGE recommends the routine use of $0.1 \%$ methylene blue or $0.1 \%-0.5 \%$ indigo carmine pancolonic chromoendoscopy with targeted biopsies for neoplasia surveillance in patients with long-standing colitis. In appropriately trained hands, in the situation of quiescent disease activity and adequate bowel preparation, nontargeted, four-quadrant biopsies can be abandoned (strong recommendation, high quality evidence).
4 ESGE suggests that virtual chromoendoscopy (NBI, FICE, i-SCAN) and conventional chromoendoscopy can be used, under strictly controlled conditions, for real-time optical diagnosis of diminutive ( $\leq 5 \mathrm{~mm}$ ) colorectal polyps to replace histopathological diagnosis. The optical diagnosis has to be reported using validated scales, must be adequately photodocumented, and can be performed only by experienced endoscopists who are adequately trained and audited (weak recommendation, high quality evidence).

5 ESGE suggests the use of conventional or virtual (NBI) magnified chromoendoscopy to predict the risk of invasive cancer and deep submucosal invasion in lesions such as those with a depressed component ( 0 -IIc according to the Paris classification) or nongranular or mixed-type laterally spreading tumors (weak recommendation, moderate quality evidence).

\section{Conclusion}

Advanced imaging techniques will need to be applied in specific patient groups in routine clinical practice and to be taught in endoscopic training programs. 


$\begin{array}{ll}\text { Abbreviations } \\ \text { CAC } & \text { cap-assisted colonoscopy } \\ \text { CRC } & \text { colorectal cancer } \\ \text { EMR } & \text { endoscopic mucosal resection } \\ \text { ESGE } & \text { European Society of Gastrointestinal Endoscopy } \\ \text { FAP } & \text { familial adenomatous polyposis } \\ \text { FICE } & \text { Fujinon intelligent color enhancement, flexible spec- } \\ & \text { tral imaging enhancement } \\ \text { FAP } & \text { familial adenomatous polyposis } \\ \text { GRADE } & \text { grading of recommendations assessment, develop- } \\ & \text { ment and evaluation } \\ \text { HD-WLE } & \text { high definition white-light endoscopy } \\ \text { i-SCAN } & \text { Pentax virtual chromoendoscopy system } \\ \text { MAP } & \text { MUTYH-associated polyposis } \\ \text { NBI } & \text { narrow band imaging } \\ \text { PICO } & \text { population, intervention, comparator, outcome } \\ \text { PIVI } & \text { preservation and incorporation of valuable endo- } \\ & \text { scopic innovations } \\ \text { RCT } & \text { randomized controlled trial } \\ \text { SD-WLE } & \text { standard definition white-light endoscopy } \\ \text { TER } & \text { third eye retroscope } \\ \text { WLE } & \text { white-light endoscopy }\end{array}$

\section{Introduction}

$\nabla$

Colonoscopy is widely used for colorectal cancer (CRC) detection and prevention $[1,2]$. Its efficacy depends on the ability to detect colorectal neoplasia $[3,4]$. In order to maximize the detection of colorectal neoplasia we may not only need to improve the examination technique and quality of bowel preparation but also to engage advanced imaging technologies such as high definition endoscopy, conventional or virtual chromoendoscopy, autofluorescence imaging (AFI) or add-on devices [5]. Some of these technologies may in addition help to characterize detected lesions and thereby guide decisions about endoscopic resection or enable real-time endoscopic diagnosis. Despite being readily available, most technologies have been little adopted into clinical practice outside academic settings [6], mostly because they are perceived as cumbersome, time-consuming and requiring special training. In our view, however, an important barrier to widespread adoption is the lack of a clear guideline on which technology is worth using in which clinical scenario.

This Guideline aims to provide endoscopists with a comprehensive review of advanced imaging techniques available for the detection and differentiation of colorectal neoplasia. We also make recommendations about the circumstances under which those techniques warrant introduction into routine clinical practice.

\section{Methods}

The European Society of Gastrointestinal Endoscopy (ESGE) commissioned this Guideline. The guideline development process included meetings and online discussions among members of the guideline committee during December 2012 and February 2013. Subgroups were formed, each in charge of a series of clearly defined key questions ( $\bullet$ Appendix e1, available online). The guideline committee chairs (C.H., J.M.D.) worked with the subgroup leaders (J.P., M.P., R.B., J.E., M.F.K.) to identify pertinent search terms that included: high definition endoscopy, chromoendos- copy, virtual chromoendoscopy (always including additional separate searches for NBI, FICE, and i-SCAN), autofluorescence endoscopy, and add-on devices (cap-assisted colonoscopy, Third Eye Retroscope [TER]), as well as terms pertinent to specific key questions. Techniques still under development, such as confocal laser endomicroscopy, endocytoscopy, and optical coherence tomography, were not included in this Guideline. Technical aspects of advanced imaging technologies will be described in a separate technology review; they are summarized in $\bullet$ Table 1 . For ease of literature searching, key questions were formulated using PICO methodology [7].

Searches were performed on Medline (via Pubmed) and the Cochrane Central Register of Controlled Trials up to October 2012; additionally abstracts from the 2012 United European Gastroenterology Week and the 2012 Digestive Disease Week were searched. Articles were first selected by title; their relevance was then assessed by reviewing full-text articles, and publications with content that was considered irrelevant were excluded. Evidence tables were generated for each key question, summarizing the level of evidence of the available studies. For important outcomes, articles were individually assessed by using the Grading of Recommendations Assessment, Development and Evaluation (GRADE) system for grading evidence levels and recommendation strengths [8]. The GRADE system is clinically orientated as the grading of recommendations depends on the balance be-

Table 1 Summary of characteristics of advanced imaging techniques.

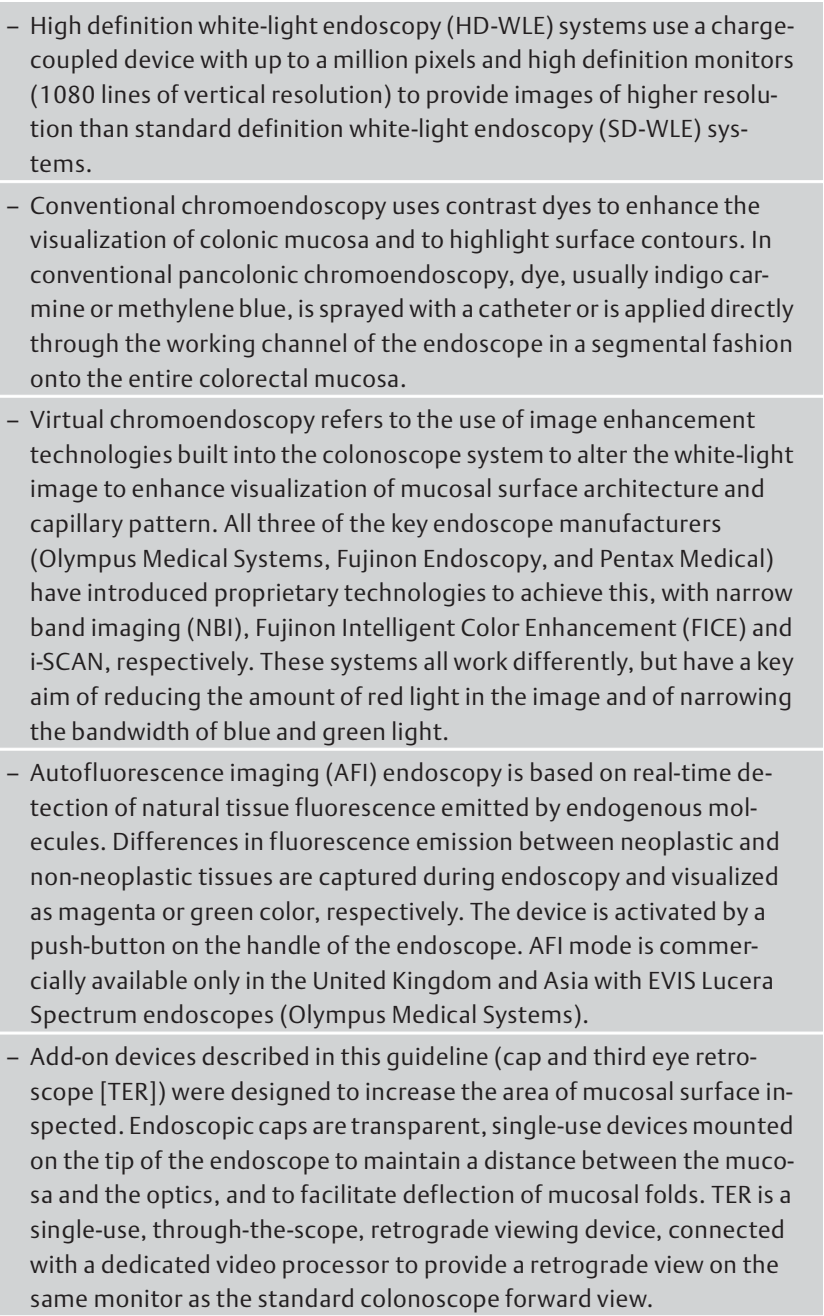




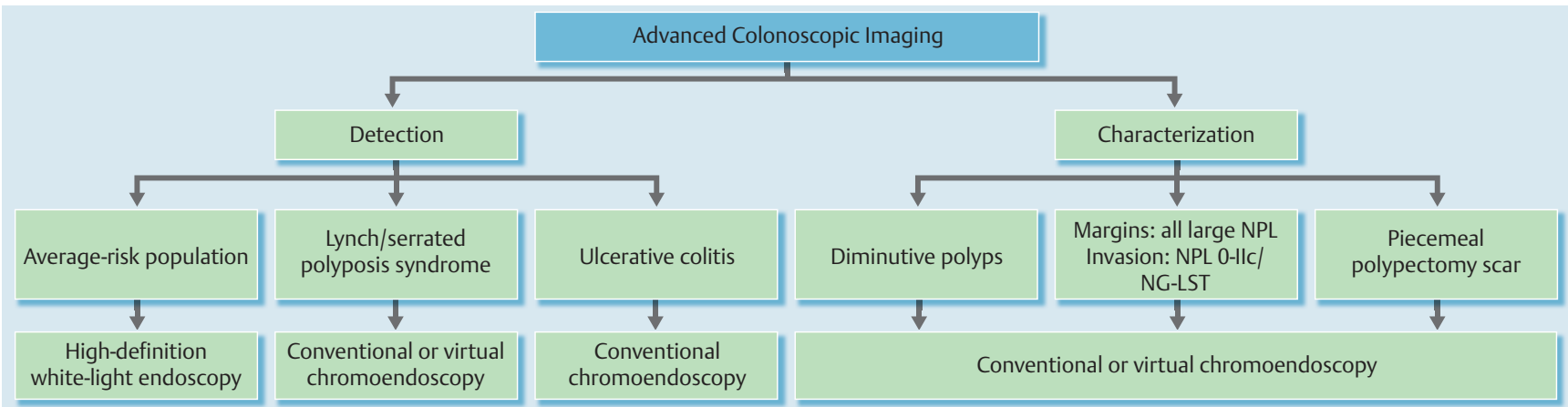

Fig. 1 Summary of the recommendations. NPL, nonpolypoid lesion; 0-Ilc, lesions with a depressed component; NG-LST, non-granular laterally spreading tumor.

tween benefits and risks or burden of any health intervention ( $\bullet$ Appendix e2 a,b, available online). In order to answer the question on accuracy of virtual chromoendoscopy systems and AFI in differentiating between small neoplastic and non-neoplastic colorectal polyps, one of the subgroups performed a bivariate meta-analysis using a linear mixed model approach [9].

Each subgroup developed draft proposals that were presented to the entire group for general discussion during a meeting held in February 2013 (Düsseldorf, Germany). Based on evidence tables and draft proposals, key topics for further research were formulated. Further details on the methodology of ESGE guidelines have been reported elsewhere [10].

In October 2013, a draft prepared by M.F.K. and C.H. was sent to all group members. After agreement on a final version, the manuscript was submitted to the journal Endoscopy for publication. The journal subjected the manuscript to peer review, and the manuscript was amended to take into account the reviewers' comments. The final revised manuscript was agreed upon by all the authors.

This Guideline was issued in 2014 and will be considered for update in 2017. Any interim updates will be noted on the ESGE website: http://www.esge.com/esge-guidelines.html.

\section{Recommendations and statements}

Evidence statements and recommendations are stated in italics, key evidence statements and recommendations are in bold. For ease of clinical use, recommendations and statements were grouped into five categories defined by target population and/or the role of advanced imaging for detection and/or differentiation of colorectal neoplasia. Statements on the use of virtual chromoendoscopy mention in parentheses the type of technology (NBI, FICE or i-SCAN), which was proven to be effective. The summary of the recommendations is presented in $\bullet$ Fig. 1 .

\section{Detection of colorectal neoplasia in average risk populations \\ $\nabla$}

The term "average risk population" is most widely used in the setting of CRC screening [11, 12]. For the purpose of this Guideline, this term applies to all patients outside the setting of colitis or hereditary syndromes. As a large number of colonoscopies are performed in average risk populations [13], even minor increases in neoplasia detection rates achieved in this population may translate into a large effect on absolute numbers of CRC prevented. On the other hand, an advanced imaging technology should be very practical and cost-effective in order not to overload already stressed health care systems if it is to be recommended for average risk populations.

ESGE suggests the routine use of high definition white-light endoscopy systems for detecting colorectal neoplasia in average risk populations (weak recommendation, moderate quality evidence).

A meta-analysis of five studies that included 4422 average risk patients showed a $3.5 \%$ (95\% confidence interval [95\%CI] 0.9\%$6.1 \%$ ) incremental yield from high definition white-light endoscopy (HD-WLE) over standard definition white-light endoscopy (SD-WLE) for the detection of patients with at least one adenoma [14]. There were no differences between HD-WLE and SD-WLE for high risk adenomas. We postulate that the difference in the fields of view of the endoscopes that were used is unlikely to account for the increased yield observed with HD-WLE because three randomized controlled trials (RCTs), from two centers, found no significant difference in polyp detection rates between SD-WLE with $140^{\circ}$ and $170^{\circ}$ fields of view [15 - 17]. In a two-center RCT published after the meta-analysis [18], the proportion of participants in whom adenomas were detected was higher with HD-WLE compared with SD-WLE (45.7\% vs. $38.6 \% ; P=0.166$ ) and the difference was significant in the proportions of patients with flat adenomas (9.5\% vs. $2.4 \% ; P=0.003$ ) and with right-sided adenomas $(34.0 \%$ vs. $19.0 \% ; P=0.001)$. The cost-effectiveness of adopting HD-WLE in routine practice was not studied. High definition colonoscopes are available from all major manufacturers. ESGE does not suggest routine use of conventional pancolonic chromoendoscopy in average risk populations, despite its proven benefit, for practical reasons (weak recommendation, high quality evidence).

A recent Cochrane systematic review [19] analyzed five RCTs (total 1059 patients) that assessed the role of conventional chromoendoscopy in detecting colorectal lesions outside the setting of polyposis or colitis. Pancolonic chromoendoscopy significantly increased the number of patients with at least one polyp detected (odds ratio [OR] 2.22, 95\%CI 1.55-3.16) and of those with at least one dysplastic lesion detected (OR 1.67, 95\%Cl 1.29-2.15). A limitation of the systematic review was the significant heterogeneity observed between the studies.

Since the publication of this Cochrane systematic review, four RCTs have compared HD-WLE with conventional chromoendoscopy for detecting neoplastic lesions [20-23]. Only one of them 
[22] did not find that conventional chromoendoscopy detects significantly more adenomas than HD-WLE (32.7\% vs. $26.9 \% ; P=$ $0.47)$. However this study only evaluated the detection of adenomas located in the distal colon and in the rectum. The other three studies $[20,21,23]$ showed that chromoendoscopy increased the overall detection of adenomas, including flat and small adenomas. None of the studies showed an increased detection rate for advanced neoplastic lesions but none of them was sufficiently powered for this aim.

In expert hands, additional procedure duration associated with pancolonic chromoendoscopy was 4-10 minutes in all studies that reported this item, i.e., a $30 \%-40 \%$ increase in total procedure duration $[20,23]$. Additional costs associated with dyes, removal, and histopathological evaluation of additional non-neoplastic lesions and the increase in total procedure duration, coupled with the absence of evidence supporting an increased detection rate of advanced neoplasia, call against the routine use of pancolonic chromoendoscopy in average risk populations.

ESGE does not recommend routine use of virtual pancolonic chromoendoscopy, AFI, or add-on devices for detecting colorectal neoplasia in average risk populations (strong recommendation, high quality evidence).

\section{Virtual chromoendoscopy}

Two recent meta-analyses of RCTs compared detection [24,25] and miss rates [25] of colonic lesions in average risk populations using white-light endoscopy (WLE) and NBI. In the meta-analysis [24], of 7 RCTs, that included a total of 2936 patients, there was no significant difference in adenoma detection rate between NBI and WLE (36\% vs. $34 \%, P=0.413$; relative risk [RR] 1.06, $95 \% \mathrm{CI}$ $0.97-1.16)$. The other meta-analysis [25], included 9 RCTs [2634] (3 studies published in abstracts only), and a total of 3059 patients. This meta-analysis also showed no difference between HD-NBI and HD-WLE for the detection of adenomas (OR 1.01, $95 \% \mathrm{CI} 0.74-1.37$ ), of patients with adenomas (OR $1.0,95 \% \mathrm{CI}$ $0.83-1.20$ ), of flat adenomas (OR $1.26,95 \% \mathrm{CI} 0.62-2.57$ ), nor in the miss rate of adenomas (OR $0.65,95 \% \mathrm{CI} 0.40-1.06$ ). Two recent large, multicenter RCTs $[18,35]$ further corroborated the results of these meta-analyses.

Data on the use of FICE or i-SCAN for detection of colonic neoplasia during colonoscopy are scarce. Two RCTs [36, 37] did not find any difference between HD-FICE and HD-WLE concerning adenoma detection [36] or adenoma miss rate [37] in screening or surveillance colonoscopies. The single RCT that compared HD-iSCAN with HD-WLE for screening colonoscopy showed no significant difference either in adenoma detection or in the adenoma miss rates [38].

NBI and FICE are often criticized for darkening the endoscopy image and in turn hampering the wider view of the colon [24]. Whether newer-generation, brighter systems make a difference in adenoma detection remains to be evaluated.

\section{Autofluorescence endoscopy}

Five RCTs evaluating AFI for the detection of colorectal neoplasia in average risk patients have produced conflicting results [3943]. Details of these studies are summarized in Appendix e3 (available online). A tandem study of AFI vs. HD-WLE [41] showed significantly lower proximal adenoma miss rates with AFI. Another RCT, from Japan [42], that allocated patients to four groups: HD-WLE alone, HD-WLE+cap-assisted colonoscopy [CAC], AFI alone, AFI + CAC, found a significantly higher number of adenomas per patient in the AFI+CAC group compared with the HD-WLE alone group. In contrast, all three tandem RCTs that were conducted in Europe have not demonstrated differences in colorectal adenoma miss rates between AFI and HD-WLE in academic settings $[40,43]$ or between AFI and SD-WLE in a nonacademic setting [39].

\section{Add-on devices}

Four meta-analyses, published in 2011 and 2012, have compared the efficacy of CAC with that of regular colonoscopy [44-47]. Three of them [44-46] included between 7 and 14 RCTs for the analysis of detection of colorectal lesions; one considered available data regarding polyp detection not adequate for meta-analysis [47]. All three meta-analyses demonstrated a significantly higher polyp detection rate (by $8 \%-13 \%$ ) but no difference in the adenoma detection rate between CAC and regular colonoscopy. Therefore, the role of CAC for the detection of colorectal neoplasia is limited.

One multicenter, tandem colonoscopy RCT compared the detection of adenomas using the "third eye" retroscope (TER) with regular colonoscopy in an average risk population [48]. The per-protocol analysis showed that more adenomas were missed with regular colonoscopy compared with the TER (RR 1.92; 95\%CI $1.07-3.44$ ) but the difference was not statistically significant in the intention-to-treat analysis ( $R R 1.46, P=0.185$ ). The total procedure and withdrawal times were 4 and 2 minutes longer with TER, respectively, because of device manipulation and additional polypectomies. The utility of TER in routine practice is further limited by technical difficulties with the use of the device in $5 \%$ of patients [48], impaired ability to aspirate luminal contents, relatively high cost [49], and limited availability.

\section{Detection of colorectal neoplasia in hereditary syndromes \\ $\nabla$}

Advanced imaging, compared with regular colonoscopy, can potentially help in hereditary syndromes in two principal ways. First, it can assist in making a diagnosis by revealing additional lesions required to meet diagnostic criteria for sessile serrated and adenomatous polyposis syndromes [50,51]. Second, when a hereditary CRC syndrome is diagnosed and surveillance is undertaken, advanced imaging may lead to better lesion detection thereby reducing the risk of interval cancer [52] or allowing the safe extension of surveillance intervals.

ESGE recommends the routine use of high definition pancolonic chromoendoscopy in patients with known or suspected Lynch syndrome (conventional chromoendoscopy, NBI, i-SCAN) or serrated polyposis syndrome (conventional chromoendoscopy, NBI) (strong recommendation, low quality evidence).

Patients and family members with Lynch syndrome or serrated polyposis syndrome are recommended frequent, usually annual to biennial colonoscopy surveillance $[53,54]$ in order to minimize the risk of developing interval cancer $[55,56]$. In both syndromes, precursor lesions are more likely to be nonpolypoid, located proximally, and difficult to recognize $[54,57,58]$. Four small tandem colonoscopy studies [59-62], showed higher detection rates of adenomas [59-61] or polyps [62] with conventional chromoendoscopy compared with SD-WLE or HD-WLE in patients with Lynch syndrome, at the cost of additional time (range 1.8 to 17 
minutes per case) (the studies are summarized in $\bullet$ Appendix e4, available online).

The role of virtual chromoendoscopy in patients with Lynch syndrome was assessed in two prospective cohort studies [61, 63] and one RCT [64]. In the first cohort study [63] an additional pass with NBI significantly increased the proportion of patients detected with adenomas (absolute difference 15\%, 95\%CI 4\%$25 \%$ ) compared to a single pass with HD-WLE. In the other cohort study [61] the total numbers of adenomas and flat adenomas detected by a second pass with conventional chromoendoscopy were significantly higher than with a first pass using HD-NBI. In a tandem RCT [64] the miss rate of polyps was significantly lower with i-SCAN compared with HD-WLE (16\% vs. 52\%, respectively; $P<0.01$ ).

A tandem RCT compared specifically AFI (Xillix Technologies Corporation) with HD-WLE in patients with Lynch syndrome or familial CRC [65]. The sensitivity for the detection of adenomas was significantly higher with AFI compared with HD-WLE $(92 \%$ vs. $68 \%, P=0.01$ ). The AFI system used in this study is not widely commercially available. Although there are no studies that have assessed conventional chromoendoscopy in sessile serrated polyposis, a review that summarized serrated lesion detection in an average risk population suggested that conventional chromoendoscopy doubled the detection rate of serrated lesions, overall and in the proximal colon (no differentiation between hyperplastic and sessile serrated polyps was made) [51]. One tandem colonoscopy RCT in patients with sessile serrated polyposis [66] showed significantly lower polyp miss rates with HD-NBI compared with HD-WLE (OR 0.21; 95\%CI 0.09-0.45). One pilot study showed suboptimal diagnostic accuracy of AFI in differentiation between sessile serrated polyps, hyperplastic polyps, and adenomas [67].

ESGE does not make any recommendation for the use of advanced endoscopic imaging in patients with suspected or known familial adenomatous polyposis (FAP) including attenuated and MUTYHassociated polyposis (insufficient evidence to make a recommendation).

Patients with classical FAP have hundreds of adenomas uniformly distributed in the colorectum while those with attenuated FAP and MUTYH-associated polyposis (MAP) have much fewer, more proximally distributed, adenomas. For surveillance, sigmoidoscopy is recommended in patients with classical FAP and colonoscopy in those with attenuated FAP or with MAP $[68,69]$. In patients with classical FAP, conventional and virtual chromoendoscopy increase the detection rate of adenomas compared with HD-WLE [70]; however the clinical usefulness of these techniques is limited, because of the recommendation for proctocolectomy early in the course of the disease. In the context of attenuated FAP and of MAP, the usefulness of these techniques during surveillance is unknown.

Following proctocolectomy for FAP, small adenomas are better detected in the ileal pouch with conventional chromoendoscopy $[71,72]$ but the clinical significance of this finding is unclear.

\section{Detection and differentiation of colorectal neoplasia in long-standing inflammatory bowel disease}

$\nabla$

Patients with long-standing left-sided or extensive ulcerative colitis or extensive Crohn's colitis are recommended to have intensive colonoscopic surveillance because of an increased risk of CRC compared with the average risk population $[53,73]$. Advanced imaging may be of benefit by: (i) increasing the detection of dysplasia [74]; (ii) improving the differentiation of lesions (colitis associated neoplasia, sporadic neoplasia $[75,76]$, and non-neoplastic lesions); and (iii) reducing the number of unnecessary biopsies.

ESGE recommends the routine use of $0.1 \%$ methylene blue or $0.1 \%$ $0.5 \%$ indigo carmine pancolonic chromoendoscopy with targeted biopsies for neoplasia surveillance in patients with long-standing colitis. In appropriately trained hands, in the situation of quiescent disease activity and adequate bowel preparation, nontargeted fourquadrant biopsies can be abandoned (strong recommendation, high-quality evidence).

Two sufficiently powered RCTs compared the diagnostic yield of conventional chromoendoscopy and SD-WLE $[77,78]$. Additionally, one high quality meta-analysis [79] including these two RCTs and four cohort studies confirmed the overall findings in 1277 patients from a well-defined target population (disease duration $>8$ years). In the meta-analysis the pooled incremental yield of conventional chromoendoscopy with random biopsies over SD-WLE with random biopsies for the detection of patients with neoplasia was 7\% (95\%CI 3.2\%-11.3\%). Moreover, the difference in proportion of lesions detected by targeted biopsies only was $44 \%$ (95\%CI $28.6 \%-59.1 \%$ ) in favor of conventional chromoendoscopy. Two prospective cohort studies [80, 81] published after the meta-analysis further corroborated the results. Overall, in 8 prospective studies comparing conventional chromoendoscopy with SD-WLE, the former consistently increased the proportion of patients found with dysplasia with a factor $2.08-3.26[77-81]$.

Although in all the abovementioned studies [77-81] random four-quadrant biopsies were taken as a back-up method in conjunction with chromoendoscopy-targeted biopsies, the diagnostic yield of those back-up biopsies was rather limited. The pooled sensitivity for the detection of neoplasia with chromoendoscopytargeted biopsies only was $86 \%$ (range $71 \%-100 \%$ ) for all studies that reported this data and 95\% (range 87\%-100\%) after exclusion of one study [82] in which targeted rather than pancolonic chromoendoscopy was used ( Appendix e5, available online; $[77,78,80-82,83,84,85])$. The median number of targeted biopsies sampled per procedure was 1.3 (range $0.28-14.2$ ) and the median number of targeted plus random biopsies per procedure was 34.3 (range $7.0-42.2$ ).

The number of biopsies needed during conventional chromoendoscopy surveillance of long-standing colitis can therefore be significantly reduced if only targeted biopsies are taken. The case for abandoning random biopsies is further supported by evidence of poor adherence to endoscopic protocols for random biopsies in clinical practice [86]. There is however no evidence to show what the process of pancolonic chromoendoscopy training and abandoning random biopsies should look like. It has been suggested during expert discussion at the Disease Digestive Week 2009 (T.A. Ullman and R. Kiesslich) that the following logical steps should be undertaken: (i) chromoendoscopy training with an expert on at least 30 colonoscopies; (ii) chromoendoscopy with targeted and random biopsies; (iii) chromoendoscopy with random biopsies in special situations only (multiple post-inflammatory polyps, neoplasia on previous colonoscopy, etc); and (iv) chromoendoscopy with targeted biopsies only.

In studies summarized in the meta-analysis cited above [79], the duration of surveillance colonoscopy in long-standing colitis was 
longer with pancolonic chromoendoscopy plus random biopsies compared with SD-WLE with random biopsies, by an average 11 minutes ( $95 \% \mathrm{CI} 10 \mathrm{~min} 15 \mathrm{~s}$ to $11 \mathrm{~min} 43 \mathrm{~s}$ ). It is likely, however, that the duration of pancolonic chromoendoscopy with only targeted biopsies is comparable to or shorter than that of WLE with random biopsies $[84,85]$.

In all prospective studies [77-81] $0.1 \%$ methylene blue or 0.1 $0.5 \%$ indigo carmine solutions were used for chromoendoscopy, with no evidence for difference in their efficacy. Some concern was raised by a report on oxidative DNA damage in Barrett's epithelium caused by methylene blue in combination with photosensitization by WLE [87], but there is no clinical evidence indicating an increased risk in patients with long-standing colitis.

Limitations of conventional chromoendoscopy in the context of long-standing colitis surveillance needs to be mentioned. There is no proof that better detection of neoplasia by conventional chromoendoscopy translates into reduced CRC mortality or decreased risk of interval CRC. Cost-effectiveness is also unclear for chromoendoscopy compared to WLE plus random biopsies, although it may be cheaper when combined with risk stratification thereby entailing fewer colonoscopies and fewer histological samples [88]. It is unknown whether there would be any benefits of conventional chromoendoscopy over WLE with newer-generation HD-WLE colonoscopes. Several prerequisites are listed in the SURFACE guidelines [89], such as quiescent disease and excellent bowel preparation, which must be met in the performance of pancolonic chromoendoscopy surveillance. Nevertheless the use of pancolonic chromoendoscopy with only targeted biopsies for dysplasia detection in colitis is now strongly endorsed by the British Society of Gastroenterology [90], and the European Crohn's and Colitis Organization [91].

ESGE found insufficient evidence to recommend for or against the use of virtual chromoendoscopy or autofluorescence imaging (AFI) for the detection of colorectal neoplasia in inflammatory bowel disease (insufficient evidence to make a recommendation).

Three RCTs compared virtual chromoendoscopy (NBI in all cases) with WLE for the detection of neoplasia in long-standing inflammatory bowel disease [92-94]. Regardless of generation of NBI and the level of definition of colonoscopes used, virtual chromoendoscopy did not significantly increase the detection rate of neoplastic lesions compared with WLE [92-94]. However, in all three RCTs, virtual chromoendoscopy with targeted biopsies alone yielded neoplasia detection rates comparable to WLE with targeted and nontargeted four-quadrant biopsies [92 - 94]. Mean number of biopsies per patient was 0.5 to 3.5 in NBI with targeted biopsies only and 24.6 to 38.3 in WLE with targeted and random quadrantic biopsies [92, 94].

Two RCTs compared an HD-NBI system with high definition conventional chromoendoscopy, both without nontargeted biopsies, for the detection of neoplasia in long-standing inflammatory bowel disease [95, 96]. The first study was a single-center, crossover RCT aimed at comparing neoplasia miss rates with HD-NBI and high definition conventional chromoendoscopy [95]. The miss rate of neoplastic lesions was considerably higher with HDNBI compared with high-definition conventional chromoendoscopy ( $31.8 \%$ and $13.6 \%$, respectively) but the study was not powered enough to test the observed difference for statistical significance. The second study was a multicenter, parallel group RCT aimed at comparing neoplasia detection rates with HD-NBI and high definition conventional chromoendoscopy [96]. Preliminary results (108 of 134 planned patients have been included) showed similar neoplasia detection rates for NBI and conventional chro- moendoscopy, per lesion $(24.0 \%$ and $17.2 \%$, respectively; $P=$ 0.385 ) and per patient (18.5\% and $16.7 \%$, respectively). Median withdrawal time was significantly shorter in the NBI group compared to the chromoendoscopy group ( 21 vs. 27 minutes, respectively; $P=0.003$ ).

There were only two studies, of which one was an RCT, comparing HD-WLE with AFI for the detection of colorectal neoplasia in inflammatory bowel disease [94, 97]. A pilot study [97] showed that protruding lesions with a low autofluorescence signal were significantly more likely to be neoplastic than lesions with a high autofluorescence signal ( $45.0 \%$ vs. $13.3 \%$, respectively, $P=0.043$ ). In the RCT, the miss rate for neoplastic lesions was statistically significantly lower with AFI compared with HD-WLE (0\% vs. $50 \%$, $P=0.036$ ). It should be noted that inadequate bowel preparation and active inflammation interrupt tissue autofluorescence, resulting in discoloration on AFI and resembling neoplasia [97]. Further studies including comparison with conventional chromoendoscopy are needed.

ESGE recommends taking biopsies from flat mucosa surrounding neoplastic lesions and taking biopsies from or resecting all suspicious lesions identified at neoplasia surveillance in long-standing colitis, because there is no evidence that nonmagnified conventional or virtual chromoendoscopy can reliably differentiate between colitis-associated and sporadic neoplasia or between neoplastic and non-neoplastic lesions (strong recommendation, low to moderate quality evidence).

\section{Neoplastic vs. non-neoplastic lesions}

A modified pit pattern classification has been used in three conventional chromoendoscopy studies to differentiate between neoplastic and non-neoplastic lesions in long-standing inflammatory bowel disease $[77,80,82]$. The surface staining pattern allowed differentiation between neoplastic and non-neoplastic lesions with high sensitivity and specificity (93\%-100\% and $88 \%-$ $97 \%$, respectively) $[77,80,82]$. However, in the reported studies magnifying endoscopes, which are not widely available, were used for lesion characterization and total procedure times were on average 9-11 minutes longer. No studies report on differentiation between neoplastic and non-neoplastic lesions in inflammatory bowel disease using nonmagnifying colonoscopes with conventional chromoendoscopy.

Four studies evaluated the role of non-magnified NBI in differentiating neoplastic and non-neoplastic lesions in patients with long-standing colitis [94,98-100]. One case report [100] and one pilot study [99] showed that a tortuous pit pattern and a high vascular pattern intensity may help to distinguish neoplastic and non-neoplastic lesions in long-standing colitis. In two small RCTs $[94,98]$ the sensitivity and specificity of NBI in predicting histology were unsatisfactory. In one of these RCTs [94] combining AFI with NBI increased sensitivity for predicting histology from $75 \%$ to $100 \%$ without a major drop in specificity. No other virtual chromoendoscopy systems were assessed for differentiation of lesions in the setting of colitis.

\section{Colitis-associated vs. sporadic neoplasia}

Current guidelines suggest taking biopsies from the flat mucosa surrounding neoplastic lesions in long-standing colitis, because differentiation between colitis-associated and sporadic neoplasia is crucial in determining their optimal management $[73,90]$. Although it has been suggested that conventional chromoendoscopy cannot distinguish these two entities because of a similar staining pattern [89], it has recently been shown that magnifying 
conventional chromoendoscopy combined with NBI can be useful for this purpose if the borders of the circumscribed lesion are thoroughly assessed [75]. This finding has to be confirmed by larger and more robust studies.

\section{Differentiation between neoplastic and non-neoplastic diminutive colorectal polyps \\ $\nabla$}

It is current practice to resect all colorectal polyps and to send them for histological analysis. This is expensive and generates a large burden of work for histopathology departments. In considering diminutive polyps ( $\leq 5 \mathrm{~mm}$ in size), which represent approximately $60 \%$ of all polyps detected at primary screening colonoscopy [101, 102], the main goal of histological examination is to differentiate between neoplastic and non-neoplastic lesions in order to determine the need and timing for surveillance colonoscopy. Techniques for optical diagnosis using advanced imaging have been developed which have the potential to supplement or replace formal histological diagnosis with in vivo optical diagnosis [103-105]. A "resect and discard" policy has been proposed which suggests making a real-time optical diagnosis of diminutive colorectal polyps using advanced imaging, photodocumenting them, and resecting and discarding them without histological assessment [103]. This could not only reduce costs for histological assessment but also allow an immediate recommendation regarding the interval to the next colonoscopy [106]. It was further proposed to photodocument and leave in situ diminutive polyps in the rectosigmoid region considered to be non-neoplastic at optical diagnosis [106]. A recent statement from the American Society for Gastrointestinal Endoscopy [106] (Preservation and Incorporation of Valuable endoscopic Innovations [PIVI] statement) has attempted to set standards against which a technology should be assessed in order to be deemed suitable for applying a policy of resect and discard ( $\geq 90 \%$ agreement in assignment of post-polypectomy surveillance intervals when compared with decisions based on pathology assessment) or a policy of leaving suspected non-neoplastic polyps in place ( $\geq 90 \%$ negative predictive value, when used with high confidence).

\section{ESGE suggests that virtual chromoendoscopy (NBI, FICE, i-SCAN) and conventional chromoendoscopy can be used, under strictly controlled conditions, for real-time optical diagnosis of diminutive $(\leq 5 \mathrm{~mm})$ colorectal polyps to replace histopathological diagnosis. The optical diagnosis has to be reported using validated scales, must be adequately photodocumented, and can be performed only by experienced endoscopists who are adequately trained and audit- ed (weak recommendation, high quality evidence).}

Major concerns regarding the use of optical diagnosis techniques are that advanced pathology (i.e. high grade dysplasia, tubulovillous or villous morphology) and cancers might be missed, leading to setting of inappropriate surveillance intervals or suboptimal treatment. However, the risk estimates for advanced pathology are low for polyps $\leq 5 \mathrm{~mm}$ in size (ranging from $0.1 \%$ to $26 \%$, with most estimates tending towards the lower end of this range; - Appendix e6, available online; [102,105,107-132]). Moreover, data are limited on the importance of advanced pathology in small and diminutive polyps in terms of the future risk of advanced pathology or cancer. This is further confounded by the poor agreement between even expert pathologists for the diagnosis of villosity or high grade dysplasia, with 10 -fold variation in rates [133-135]. Given this variability, British guidelines have chosen to ignore these characteristics and use size only as a criterion, and United European guidelines have chosen to add them as accessory criteria, whereas the ESGE and American guidelines use these features to determine surveillance intervals $[90,136-$ 138]. A second concern is the rate of carcinoma in diminutive polyps which is very low but not negligible (the risk estimate for lesions $\leq 5 \mathrm{~mm}$ ranges from $0 \%$ to $0.6 \%$, again with most estimates at the lower end of the range; see the summary of evidence in - Appendix e6). Although it is unknown whether diminutive cancer polyps harbor the same characteristics as larger cancer polyps at endoscopic examination, it is generally recommended that optical biopsy be avoided in suspicious lesions (e.g. depressed lesions, Paris classification 0-IIc) [139], which might further reduce the risk of missing a cancer.

A meta-analysis that included 56 studies [9] showed that the overall sensitivity and specificity of NBI for differentiation between neoplastic and non-neoplastic colorectal polyps were 91.0\% (95\%CI 88.6\%-93.0\%) and 85.6\% (95\%CI 81.3\%-89.0\%), respectively. In a subset of real-time assessment studies, the negative predictive value (NPV) was $82.5 \%$ (95\%CI 75.4\%-87.9\%). For FICE, this meta-analysis included 14 studies; the corresponding overall sensitivity, specificity and NPV were 91.8\% (95\%Cl $87.1 \%-94.9 \%), 83.5 \%$ (95\%CI $77.2 \%-88.3 \%)$, and $83.7 \%$ (95\%Cl $77.5 \%-88.4 \%$ ). For i-SCAN this meta-analysis included 10 studies; the corresponding overall sensitivity, specificity and NPV were $89.3 \%$ (95\%CI 83.3\%-93.3\%), 88.2\% (95\%CI 80.3\%-93.2\%), and $86.5 \%$ (95\%CI $78.0 \%-92.1 \%$ ). For AFI this meta-analysis included 11 studies; the corresponding overall sensitivity, specificity and NPV were 86.7\% (95\%CI 79.5\%-91.6\%), 65.9\% (95\%CI $50.9 \%-78.2 \%$ ), and $81.5 \%$ (95\%CI $54.0 \%-94.3 \%$ ). There were no significant differences between real-time versus post-procedure studies [9]. The effect of high definition on diagnostic performance of real-time assessments remains uncertain $[9,140]$. The abovementioned results for NBI are in accordance with those reported in another recent meta-analysis [141]. The diagnostic performance of optical diagnosis for NBI, FICE and i-SCAN (not AFI) would be acceptable for clinical use according to PIVI requirements and it should be possible to estimate surveillance intervals with NBI, FICE or i-SCAN with at least $90 \%$ accuracy [106]. Although NPVs did not quite meet the $90 \%$ standard set in the PIVI, most studies looked at polyps throughout the colon and not just rectosigmoid diminutive lesions. Conventional chromoendoscopy shows similar accuracy in differentiating between neoplastic and non-neoplastic polyps [36, 142], but because of inconvenience and costs associated with the use of dyes it is unlikely to be adopted in routine clinical practice.

Although there is now significant evidence for using virtual chromoendoscopy-based optical diagnosis, most data come from enthusiasts or experts and may not represent the actual performance by community gastroenterologists [143-145]. Indeed available data suggest a significant interobserver variability ( $\bullet$ Appendix e7, available online; [104,121,122,124,146-152]) and learning curve $[153,154]$, which can to some extent be rapidly surmounted with training [155-158], but achievement of the performance reported by experts may take longer [143]. No universal training system for differentiation between neoplastic and non-neoplastic colorectal polyps has yet been established, but all of three computer-based training modules using still photographs $[155,156,158]$ achieved significant improvement in accuracy, and one using videos resulted in improvements both in accuracy and in the number of "high confidence" assessments 
[157]. With the use of validated scales, such as the NBI International Colorectal Endoscopic (NICE) classification [159], diagnostic accuracy of in vivo optical diagnosis will likely improve, and interobserver variability decrease. However, it has to be emphasized that new or updated scales should incorporate sessile serrated polyps/adenomas in their classification systems [160].

Computer algorithms that analyze the polyp image may be able to support clinician decision making at optical biopsy and help community-based gastroenterologists to meet the required standards. Four studies reported on the diagnostic performance of computer-aided classification systems for NBI images, showing $82 \%-98 \%$ sensitivity and $61 \%-98 \%$ specificity for differentiation between neoplastic and non-neoplastic colorectal polyps [161164]. Computer-aided diagnostic performance appears to be improving with two recent large NBI studies reporting diagnostic accuracy equivalent to expert readers $[163,164]$; however magnifying endoscopes were used in these studies, making use in the community challenging.

There are currently no data to suggest what kind of documentation is needed for the resect and discard policy. The PIVI document [106] stated that, as an endoscopic photograph rather than a histology slide becomes the record of a small polyp, photographs must be stored to be used not only as evidence of adenoma detection but also of accuracy of optical diagnosis. This poses significant challenges at present, especially with regard to recording in high definition and the available disk space on servers in endoscopy units.

There is moderate quality evidence from several large and well conducted studies that in vivo optical diagnosis using NBI or FICE would be a cost-effective alternative to histology especially for diminutive polyps [103, 165-167] ( Appendix e8, available online). No studies to date have looked at i-SCAN for this purpose, although it shows a similar degree of accuracy as NBI and hence the findings on cost-effectiveness would be transferable. Two British prospective cohort studies $[103,166]$ and one American retrospective multicenter cohort study [165] showed a simple reduction in costs of histopathology of $€ 62-€ 210$ per colonoscopy associated with the use of a resect and discard policy. A Markov modelling study showed that a resect and discard policy applied to a US screening population [167] would allow for annual undiscounted savings of $\$ 33$ million/year ( $\$ 25$ [€20]/person) with negligible impact on surveillance intervals or screening efficacy. Concerns associated with the data used for model analysis include: (i) the use of US and UK models of screening for CRC, which may not be simply transferred to the various screening programs in use in Europe; (ii) the use of assumptions derived from studies performed by experts; and (iii) the exclusion of costs associated with implementation of the resect and discard policy (training for and photodocumentation of real-time diagnosis).

\section{Advanced endoscopic imaging in the treatment of neoplasia \\ $\nabla$}

Advanced endoscopic imaging techniques can be particularly suited for optimizing the endoscopic resection of large sessile or nonpolypoid colorectal lesions and for post-resection surveillance. Such lesions scheduled for endoscopic resection require adequate delineation of margins, prediction of the risk of invasive cancer and deep submucosal invasion, and thorough post-resection surveillance for residual neoplasia. These lesions should be removed by level 4 competent endoscopists [168], who usually work at tertiary referral centers, where advanced endoscopic imaging is often readily available.

ESGE suggests the use of conventional or virtual (NBI) magnified chromoendoscopy to predict the risk of invasive cancer and deep submucosal invasion in lesions such as those with a depressed component (0-Ilc according to the Paris classification) or nongranular or mixed-type laterally spreading tumors (weak recommendation, moderate quality evidence).

Superficially invasive submucosal CRCs are amenable to endoscopic resection under strictly controlled criteria [169, 170]. Advanced endoscopic imaging may help to differentiate between noninvasive lesions and superficially invasive submucosal cancers so that the appropriate endoscopic removal technique can be used and the resection site tattooed. In addition, advanced imaging may help to predict the risk of deep submucosal cancer which is associated with increased risk of lymph node metastases and perforation and bleeding, and requires surgical treatment [169-171].

\section{Risk of submucosal invasion}

Certain mucosal and vascular patterns of colorectal lesions have been associated with the risk of submucosal (or deeper) cancer being found at histological examination [172,173]. At magnifying chromoendoscopy, a Kudo $\mathrm{V}$ pit pattern predicted a substantially higher risk of invasive cancer compared with non- $V$ pit patterns (II - IV). In detail, pit pattern $\mathrm{V}$ has been associated with a risk of deep submucosal cancer greater than $40 \%$, and it has been further divided in two subtypes, namely Vi (irregular) and Vn (nonstructured), which have been associated with a $20 \%-30 \%$ and $>90 \%$ risk of submucosal invasion, respectively $[172,174-$ 176]. The sensitivity of pit pattern $V$ for the diagnosis of submucosal (or deeper) cancer was $85 \%$ in a large Japanese series and $79 \%$ in a European cohort study $[176,177]$. A few studies also addressed whether the classification of the vascular pattern or combined vascular-surface pattern of the lesion at magnifying virtual chromoendoscopy was able to predict the risk of underlying malignancy. In Japanese series, an irregular or a sparse vascular pattern on magnified NBI have been associated, with a $50 \%$ or $>90 \%$ risk, respectively, of submucosal (or deeper) cancer, such risk being marginal in those lesions with other vascular patterns $[173,178,179]$.

\section{Depth of submucosal invasion}

Several endoscopic studies addressed whether mucosal or vascular patterns at magnifying chromoendoscopy are able to predict the level of submucosal invasion. A Japanese series showed that pit pattern Vn was highly predictive of deep submucosal invasion (100\%), whilst such a risk broadly ranged between $17 \%-85 \%$ in those with pit pattern $\mathrm{Vi}$ [176]. For this reason, it has been proposed to further subclassify pit pattern $\mathrm{Vi}$, according to the severity of the irregularity in the mucosal pattern. In particular, the risk of deep submucosal invasion has been shown to be very high in those with more severe irregularity $[175,180,181]$.

Factors other than pit pattern have also been considered as predictors of deep submucosal invasion at magnifying colonoscopy. Two studies showed that some morphological characteristics at magnifying colonoscopy-including fold convergence, an expansive appearance, an irregular surface contour, a demarcated depressed area, or a $>1 \mathrm{~cm}$ nodule - predicted deep submucosal invasion with a higher sensitivity and equal specificity compared 
with the nonlifting sign $[182,183]$. In a recent large prospective analysis, combined mucosal and morphological invasive patterns at magnifying conventional chromoendoscopy have been confirmed to be highly predictive of deep submucosal invasion with a $98.8 \%$ overall accuracy [184]. Vascular pattern at magnified NBI has also been associated with the depth of cancer invasion. In particular, an irregular/sparse or severely irregular pattern has been shown to be predictive of deep submucosal invasion with sensitivity and specificity of $83 \%-100 \%$ and $72 \%-100 \%$, respectively $[173,176]$.

The predictions of submucosal invasion and depth of invasion at magnified virtual or conventional chromoendoscopy have however never been compared with routine predictions made by endoscopists at nonmagnified WLE, which means that we do not know the added value of advanced imaging over routine practice. Moreover, magnifying colonoscopes are not yet widely available in Europe so the applicability of assessments based on magnified views may be limited.

Recently, an expanded NICE classification for the characterization of deep submucosal cancer has been proposed [185]. Its advantages are the use of nonmagnified views and objective criteria for assessing deep submucosal invasion. On the other hand the overall accuracy of the expanded NICE classification for diagnosing submucosal invasion was relatively low $70 \%$ and $50 \%$ high confidence predictions, with $84 \%$ and $90 \%$ accuracy for experts and trained novices, respectively), and the scale was validated using only still images. The ability to predict the risk of submucosal (or deeper) cancer using different virtual chromoendoscopy systems was not assessed.

Irrespective of the accuracy of magnified or nonmagnified virtual or conventional chromoendoscopy in predicting potential submucosal invasion, it is questionable whether such techniques should be applied to all lesions. Their clinical impact would necessarily depend also on the expected prevalence of submucosal (or deeper) invasion. In large Japanese, US, and European series, the risk of submucosal (or deeper) cancer appeared to be low $(<2 \%)$ in 0 -Ila or 0-IIb lesions, as well as in homogeneous granular-type laterally spreading tumors (LSTs) [176,186-192]. Such a risk appeared to be substantially higher (up to 36\%) for nonpolypoid lesions with a depressed component (0-IIc) and nongranular or mixed LSTs [176,186-192]. The addition of mucosal and vascular pattern stratification, using virtual or conventional chromoendoscopy, to the morphological classification of nonpolypoid lesions and presence or not of the nonlifting sign may be the most informative way to guide decisions on whether to undertake endoscopic or surgical resection.

ESGE recommends the use of virtual or conventional chromoendoscopy to define the margins of large nonpolypoid or otherwise indistinct lesions before or during endoscopic resection (strong recommendation, very low quality evidence).

Incomplete resection has been suggested to contribute significantly to the risk of interval or post-polypectomy CRC [193, 194]. Recently it has been shown that incomplete resection of $5-20 \mathrm{~mm}$ neoplastic polyps occurs in approximately $10 \%$ of cases and that this risk significantly increases with polyp size and sessile serrated histology [195]. Therefore, advanced endoscopic imaging may be particularly useful to assist with endoscopic resection of large nonpolypoid or otherwise indistinct lesions. Despite the fact that many centers commonly use conventional chromoendoscopy to delineate large sessile or nonpolypoid colorectal lesions prior to endoscopic resection (either surface staining $[196,197]$ or stain solution injection $[198,199])$ the evidence

\section{Table 2 Key topics for further research.}

1. What are the neoplasia detection rates of conventional chromoendoscopy, virtual chromoendoscopy, and autofluorescence imaging compared with high definition white-light endoscopy (HD-WLE) in patients with Lynch syndrome (tested in a multicenter, parallel group randomized controlled trial $[\mathrm{RCT}])$ ? Does advanced imaging reduce interval colorectal cancer (CRC) rates or allow extension of colonoscopy surveillance intervals?

2. What is the role of conventional or virtual chromoendoscopy in the diagnosis and surveillance of patients with sessile serrated polyposis?

3. What is the role of advanced imaging in the diagnosis of attenuated familial adenomatous polyposis (FAP) and MUTYH-associated polyposis in patients with multiple adenomas?

4. What are the neoplasia detection rates of newer-generation narrow band imaging (NBI) and other virtual chromoendoscopy systems in long-standing inflammatory bowel disease?

5. Does conventional chromoendoscopy allow the lengthening of colonoscopy surveillance intervals in long-standing colitis or reduce interval cancer rates? How should endoscopists be trained in conventional chromoendoscopy, and at what point on the learning curve can we abandon random, four-quadrant biopsies?

6 . What are the neoplasia detection rates of conventional chromoendoscopy compared with HD-WLE, autofluorescence imaging, and virtual chromoendoscopy in long-standing inflammatory bowel disease?

7. What is the role of advanced imaging in differentiation between colitis-associated neoplasia and sporadic neoplasia in long-standing inflammatory bowel disease?

8. What is the role of nonmagnified advanced imaging in differentiation between neoplastic and non-neoplastic lesions in long-standing inflammatory bowel disease?

9. What is the diagnostic accuracy of virtual chromoendoscopy for differentiation of diminutive rectosigmoid polyps? What is the performance of community endoscopists when using validated classification scales?

10. What is the diagnostic accuracy of virtual chromoendoscopy for differentiation of diminutive sessile serrated lesions from hyperplastic polyps? How should sessile serrated polyps be incorporated into new or updated classification systems?

11. What is the performance of virtual chromoendoscopy for differentiating between neoplastic and non-neoplastic diminutive polyps by community gastroenterologists using validated scales? What is the role of computer-aided diagnosis?

12. What is the diagnostic accuracy of advanced imaging techniques for detection of residual neoplasia at endoscopic mucosal resection (EMR) or piecemeal polypectomy scars?

13. What is the diagnostic accuracy of advanced imaging techniques for delineation of colorectal neoplasia before endoscopic removal?

that this results in more radical resection is very weak. One large prospective, single-center study assessed the usefulness of high magnification conventional chromoendoscopy in predicting completeness of endoscopic mucosal resection (EMR) based on pit pattern analysis of resection margins [196]. High magnification conventional chromoendoscopy yielded $80 \%$ sensitivity for predicting remnant neoplastic tissue at resection margins. In another study, high magnification endoscopy alone was used to predict remnant neoplastic tissue at piecemeal polypectomy sites, with $98 \%$ sensitivity and $90 \%$ specificity [200]. This approach, however, has never been tested against WLE assessment, and requires high magnification endoscopes. The usefulness of submucosal injection using methylene blue solution has been formally assessed only in one pilot study of 25 polyps and using subjective criteria [201]. 
No studies were found that compared focal, surface application of dyes or virtual chromoendoscopy with WLE for delineation of colorectal neoplasia before endoscopic removal. Despite the lack of evidence, conventional or virtual chromoendoscopy can be advised for delineation of colorectal lesions because it offers potential benefit at relatively low time and cost.

ESGE recommends the use of virtual or conventional chromoendoscopy in addition to white light endoscopy for the detection of residual neoplasia at a piecemeal polypectomy scar site (strong recommendation, low quality evidence).

Large sessile or nonpolypoid colon polyps are often removed in a piecemeal fashion which is associated with a mean recurrence rate of $25 \%$ [202]. Professional societies recommend endoscopic follow up at 2 to 6 months after piecemeal resection of colorectal polyps to check for residual neoplasia [136, 137]. HD-WLE alone identifies $69 \%$ to $83 \%$ of recurrences revealed by targeted and random biopsies $[202,203]$. One study on high definition virtual chromoendoscopy and one study on high magnification conventional chromoendoscopy showed that advanced imaging identified neoplastic lesions that were not detected using SD-WLE or HD-WLE alone [204, 205]. One prospective study showed that high magnification conventional chromoendoscopy without random biopsies detected all 8 recurrences evidenced over 2 years of endoscopic follow-up in patients who underwent EMR of LSTs [206]. However a recent study [203] showed poor sensitivity and specificity of high definition virtual chromoendoscopy (72\% and $78 \%$, respectively) in predicting neoplastic histology of EMR scars as compared with conventional histopathology. Further studies are needed to establish whether the diagnostic accuracies of conventional or virtual chromoendoscopy are high enough to justify abandoning biopsy of macroscopically normal EMR or piecemeal polypectomy scars.

\section{Key topics for further research} $\nabla$

Despite a thorough literature search some of the key questions remained unanswered and other research questions were formulated as a consequence of the analysis of the available evidence. - Table 2 summarizes key topics for further research in advanced imaging for the detection and differentiation of colonic neoplasia.

\section{Use of the guideline \\ $\nabla$}

Caution: In addition to the legal disclaimer applicable to all ESGE guidelines [10], it is mentioned that methylene blue is contraindicated in individuals with glucose-6-phosphate dehydrogenase deficiency.
ESGE guidelines represent a consensus of best practice based on the available evidence at the time of preparation. They may not apply in all situations and should be interpreted in the light of specific clinical situations and resource availability. Further controlled clinical studies may be needed to clarify aspects of these statements, and revision may be necessary as new data appear. Clinical consideration may justify a course of action at variance to these recommendations. ESGE guidelines are intended to be an educational device to provide information that may assist endoscopists in providing care to patients. They are not rules and should not be construed as establishing a legal standard of care or as encouraging, advocating, requiring, or discouraging any particular treatment.

Competing interests: R. Bisschops, speaker (Pentax Europe, Fujifilm and Olympus); E. Dekker, research grant and equipment on loan (Olympus), travel grant (Norgine and Tillots); J. East, advisory board (Cosmo Pharmaceuticals), speaker (Abbott Labs/Abbvie), equipment on loan (Olympus and Pentax); M. Kaminski, speaker (Olympus, Ipsen Pharmaceuticals).

\section{Institutions}

1 Department of Gastroenterology and Hepatology, Medical Centre for Postgraduate Education, Maria Sklodowska-Curie Memorial Cancer Centre and Institute of Oncology, Warsaw, Poland

2 Digestive Endoscopy Unit, Nuovo Regina Margherita Hospital, Rome, Italy

${ }^{3}$ Department of Gastroenterology, University Hospital Leuven, Leuven, Belgium

${ }^{4}$ Department of Gastroenterology and Interventional Endoscopy, Klinikum im Friedrichshain, Berlin, Germany

${ }^{5}$ Department of Gastroenterology, Institut de Malaties Digestives i Metabòliques, Hospital Clinic, Barcelona, Spain

${ }^{6}$ Department of Gastroenterology and Hepatology, Academic Medical Centre, Amsterdam, The Netherlands

Wolfson Unit for Endoscopy, St Mark's Hospital, Imperial College London, UK ${ }^{8}$ Medizinische Klinik, St. Mary Hospital, Frankfurt, Germany

${ }^{9}$ Department of Gastroenterology, Queen Alexandra Hospital, Portsmouth Hospitals NHS Trust, Portsmouth, United Kingdom

${ }^{10}$ Department of Gastroenterology, University Hospital, CHU Rennes, France

${ }^{11}$ Gedyt Endoscopy Center, Buenos Aires, Argentina

12 Translational Gastroenterology Unit, John Radcliffe Hospital, Oxford University, Oxford, United Kingdom.

\section{References}

1 Stock C, Brenner H. Utilization of lower gastrointestinal endoscopy and fecal occult blood test in 11 European countries: evidence from the Survey of Health, Aging and Retirement in Europe (SHARE). Endoscopy 2010; 42: 546-556

2 Sonnenberg A, Amorosi SL, Lacey MJ et al. Patterns of endoscopy in the United States: analysis of data from the Centers for Medicare and Medicaid Services and the National Endoscopic Database. Gastrointest Endosc 2008; 67: 489-496

3 Kaminski MF, Regula J, Kraszewska E et al. Quality indicators for colonoscopy and the risk of interval cancer. N Engl J Med 2010; 362: $1795-1803$

4 Meester RG, Corley DA, Doubeni CA et al. Impact of variation in screening colonoscopy quality on the prevention of colorectal cancer deaths. A modelling study. Gastroenterology 2013; 144: 190

5 Rex DK. Maximizing detection of adenomas and cancers during colonoscopy. Am J Gastroenterol 2006; 101: 2866-2877

6 Spiegel BM, Ho W, Esrailian E et al. Controversies in ulcerative colitis: a survey comparing decision making of experts versus community gastroenterologists. Clin Gastroenterol Hepatol 2009; 7: 168-174, 174 e1

7 Richardson WWM, Nishikawa J, Hayward R. The well-built clinical question: A key to evidence-based decisions. ACP Journal Club 1995; 123: A12-A13

8 Atkins $D$, Best $D$, Briss $P A$ et al. Grading quality of evidence and strength of recommendations. BMJ 2004; 328: 1490 
9 Wanders LK, East JE, Uitentuis SE et al. Diagnostic performance of narrowed spectrum endoscopy, autofluorescence imaging, and confocal laser endomicroscopy for optical diagnosis of colonic polyps: a metaanalysis. Lancet Oncol 2013; 14: 1337-1347 [Epub 2013 Nov 13]

10 Dumonceau JM, Hassan C, Riphaus A et al. European Society of Gastrointestinal Endoscopy (ESGE) Guideline Development Policy. Endoscopy 2012; 44: 626-629

11 Winawer S, Fletcher R, Rex D et al. Colorectal cancer screening and surveillance: clinical guidelines and rationale-Update based on new evidence. Gastroenterology 2003; 124: 544-560

12 von Karsa L, Patnick J. European Colorectal Cancer Screening Guidelines Working Group. et al. European guidelines for quality assurance in colorectal cancer screening and diagnosis: overview and introduction to the full supplement publication. Endoscopy 2013; 45: 51-59

13 Lieberman DA, Holub J, Eisen G et al. Utilization of colonoscopy in the United States: results from a national consortium. Gastrointest Endosc 2005; 62: 875-883

14 Subramanian V, Mannath J, Hawkey CJ et al. High definition colonoscopy vs. standard video endoscopy for the detection of colonic polyps: a meta-analysis. Endoscopy 2011; 43: 499-505

15 Deenadayalu VP, Chadalawada V, Rex DK. 170 degrees wide-angle colonoscope: effect on efficiency and miss rates. Am J Gastroenterol 2004; 99: 2138-2142

16 Fatima $H$, Rex DK, Rothstein $R$ et al. Cecal insertion and withdrawal times with wide-angle versus standard colonoscopes: a randomized controlled trial. Clin Gastroenterol Hepatol 2008; 6: 109-114

17 Rex DK, Chadalawada V, Helper DJ. Wide angle colonoscopy with a prototype instrument: impact on miss rates and efficiency as determined by back-to-back colonoscopies. Am J Gastroenterol 2003; 98: 2000-2005

18 Rastogi A, Early DS, Gupta $N$ et al. Randomized, controlled trial of standard-definition white-light, high-definition white-light, and narrow-band imaging colonoscopy for the detection of colon polyps and prediction of polyp histology. Gastrointest Endosc 2011; 74: 593 602

19 Brown SR, Baraza W. Chromoscopy versus conventional endoscopy for the detection of polyps in the colon and rectum. Cochrane Database Syst Rev 2010: DOI 10.1002/14651858.CD006439.pub3 CD006439

20 Pohl J, Schneider A, Vogell $H$ et al. Pancolonic chromoendoscopy with indigo carmine versus standard colonoscopy for detection of neoplastic lesions: a randomised two-centre trial. Gut 2011; 60: 485490

21 Togashi K, Hewett DG, Radford-Smith GL et al. The use of indigocarmine spray increases the colonoscopic detection rate of adenomas. J Gastroenterol 2009; 44: 826-833

22 Hashimoto K, Higaki S, Nishiahi M et al. Does chromoendoscopy improve the colonoscopic adenoma detection rate? Hepatogastroenterology 2010; 57: 1399-1404

23 Kahi CJ, Anderson JC, Waxman I et al. High-definition chromocolonoscopy vs. high-definition white light colonoscopy for average-risk colorectal cancer screening. Am J Gastroenterol 2010; 105: 1301 1307

24 Dinesen L, Chua TJ, Kaffes AJ. Meta-analysis of narrow-band imaging versus conventional colonoscopy for adenoma detection. Gastrointest Endosc 2012; 75: 604-611

25 Pasha SF, Leighton JA, Das A et al. Comparison of the yield and miss rate of narrow band imaging and white light endoscopy in patients undergoing screening or surveillance colonoscopy: a meta-analysis. Am J Gastroenterol 2012; 107: 363-370

26 Kaltenbach T, Friedland S, Soetikno R. A randomised tandem colonoscopy trial of narrow band imaging versus white light examination to compare neoplasia miss rates. Gut 2008; 57: 1406-1412

27 Rex DK, Helbig CC. High yields of small and flat adenomas with highdefinition colonoscopes using either white light or narrow band imaging. Gastroenterology 2007; 133: $42-47$

28 Inoue T, Murano M, Murano $N$ et al. Comparative study of conventional colonoscopy and pan-colonic narrow-band imaging system in the detection of neoplastic colonic polyps: a randomized, controlled trial. J Gastroenterol 2008; 43: 45-50

29 Adler A, AschenbeckJ, Yenerim T et al. Narrow-band versus white-light high definition television endoscopic imaging for screening colonos- copy: a prospective randomized trial. Gastroenterology 2009; 136 $410-416$ e1; quiz 715

30 Paggi S, Radaelli F, Amato $A$ et al. The impact of narrow band imaging in screening colonoscopy: a randomized controlled trial. Clin Gastroenterol Hepatol 2009; 7: 1049-1054

31 East JE, Ignjatovic A, Suzuki $N$ et al. A randomized, controlled trial of narrow-band imaging vs high-definition white light for adenoma detection in patients at high risk of adenomas. Colorectal Dis 2012; 14 : e771-e778

32 Stipho S, Gilani N, Ramirez F. The clinical utilty of high-definition magnification endoscopy with and without narrow band imaging for detection of colonic neoplasia. Gastrointest Endosc 2008; 67: AB130

33 Glenn T, Hoffmann BJ, Romagnuolo J et al. Does narrow band imaging (NBI) enhance colon polyp detection? Gastrointest Endosc 2005; 61: AB227

34 Inaba Y, Watari J, Okamoto Ket al. Usefulness of narrow band imaging as a digital chromoendoscopy in screening colonoscopy: a prospective pilot study. Gastrointest Endosc 2005; 61: AB228

35 Sabbagh LC, Reveiz L, Aponte D et al. Narrow-band imaging does not improve detection of colorectal polyps when compared to conventional colonoscopy: a randomized controlled trial and meta-analysis of published studies. BMC Gastroenterol 2011; 11: 100

36 Pohl J, Lotterer E, Balzer C et al. Computed virtual chromoendoscopy versus standard colonoscopy with targeted indigocarmine chromoscopy: a randomised multicentre trial. Gut 2009; 58: $73-78$

37 Chung SJ, Kim D, Song JH et al. Efficacy of computed virtual chromoendoscopy on colorectal cancer screening: a prospective, randomized, back-to-back trial of Fuji Intelligent Color Enhancement versus conventional colonoscopy to compare adenoma miss rates. Gastrointest Endosc 2010; 72: 136-142

38 Hong SN, Choe WH, Lee JH et al. Prospective, randomized, back-toback trial evaluating the usefulness of i-SCAN in screening colonoscopy. Gastrointest Endosc 2012; 75: 1011 - 1021.e2

39 Kuiper T, van den Broek FJ, Naber AH et al. Endoscopic trimodal imaging detects colonic neoplasia as well as standard video endoscopy. Gastroenterology 2011; 140: 1887-1894

40 van den Broek FJ, Fockens P, Van Eeden S et al. Clinical evaluation of endoscopic trimodal imaging for the detection and differentiation of colonic polyps. Clin Gastroenterol Hepatol 2009; 7: 288-295

41 Matsuda T, Saito Y, Fu KI et al. Does autofluorescence imaging videoendoscopy system improve the colonoscopic polyp detection rate? -a pilot study Am J Gastroenterol 2008; 103: 1926-1932

42 Takeuchi $Y$, Inoue $T$, Hanaoka $N$ et al. Autofluorescence imaging with a transparent hood for detection of colorectal neoplasms: a prospective, randomized trial. Gastrointest Endosc 2010; 72: 1006-1013

43 Rotondano G, Bianco MA, Sansone $S$ et al. Trimodal endoscopic imaging for the detection and differentiation of colorectal adenomas: a prospective single-centre clinical evaluation. Int J Colorectal Dis 2012; 27: 331 - 336

$44 \mathrm{He}$ Q Li JD, An SL et al. Cap-assisted colonoscopy versus conventional colonoscopy: systematic review and meta-analysis. Int J Colorectal Dis 2013; $28: 279-281$

$45 \mathrm{Ng} \mathrm{SC}$, Tsoi KKF, Hirai HW et al. The efficacy of cap-assisted colonoscopy in polyp detection and cecal intubation: a meta-analysis of randomized controlled trials. Am J Gastroenterol 2012; 107: 1165 - 1173

46 Westwood DA, Alexakis N, Connor SJ. Transparent cap-assisted colonoscopy versus standard adult colonoscopy: a systematic review and meta-analysis. Dis Colon Rectum 2012; 55: 218-225

47 Morgan J, Thomas K, Lee-Robichaud $H$ et al. Transparent cap colonoscopy versus standard colonoscopy for investigation of gastrointestinal tract conditions. Cochrane Database Syst Rev 16. 02 2011; 2: DOI 10.1002/14651858.CD008211.pub2

48 Leufkens AM, DeMarco DC, Rastogi A. Effect of a retrograde-viewing device on adenoma detection rate during colonoscopy: the TERRACE study. Gastrointest Endosc 2011; 73: 480-489

49 Mamula P, Tierney WM, Banerjee $S$ et al. Devices to improve colon polyp detection. Gastrointest Endosc 2011; 73: 1092-1097

50 Wallace MH, Frayling IM, Clark SK et al. Attenuated adenomatous polyposis coli: the role of ascertainment bias through failure to dyespray at colonoscopy. Dis Colon Rectum 1999; 42: 1078-1080 
51 East JE, Saunders BP, Jass JR. Sporadic and syndromic hyperplastic polyps and serrated adenomas of the colon: classification, molecular genetics, natural history, and clinical management. Gastroenterol Clin North Am 2008; 37: 25-46

52 Jarvinen HJ, Aarnio M, Mustonen $H$ et al. Controlled 15-year trial on screening for colorectal cancer in families with hereditary nonpolyposis colorectal cancer. Gastroenterology 2000; 118: 829-834

53 Cairns SR, Scholefield JH, Steele RJ et al. Guidelines for colorectal cancer screening and surveillance in moderate and high risk groups (update from 2002). Gut 2010; 59: 666-689

54 Rex DK, Ahnen DJ, Baron JA et al. Serrated lesions of the colorectum: review and recommendations from an expert panel. Am J Gastroenterol 2012; 107: 1315-1329; quiz 1314, 1330

55 Boparai KS, Mathus-Vliegen EM, Koornstra JJ et al. Increased colorectal cancer risk during follow-up in patients with hyperplastic polyposis syndrome: a multicentre cohort study. Gut 2010; 59: 1094-1100

56 Vasen HF, Abdirahman M, Brohet R et al. One to 2-year surveillance intervals reduce risk of colorectal cancer in families with Lynch syndrome. Gastroenterology 2010; 138: 2300-2306

57 Rondagh EJ, Gulikers S, Gomez-Garcia EB et al. Nonpolypoid colorectal neoplasms: a challenge in endoscopic surveillance of patients with Lynch syndrome. Endoscopy 2013; 45: 257-264

58 Hazewinkel Y, Lopez-Ceron M, East JE et al. Endoscopic features of sessile serrated adenomas: validation by international experts using high-resolution white-light endoscopy and narrow-band imaging. Gastrointest Endosc 2013; 77: 916-924

59 Hurlstone DP, Karajeh M, Cross SS et al. The role of high-magnification-chromoscopic colonoscopy in hereditary nonpolyposis colorectal cancer screening: a prospective "back-to-back" endoscopic study. Am J Gastroenterol 2005; 100: 2167-2173

60 Lecomte T, Cellier C, Meatchi T et al. Chromoendoscopic colonoscopy for detecting preneoplastic lesions in hereditary nonpolyposis colorectal cancer syndrome. Clin Gastroenterol Hepatol 2005; 3: 897902

61 Huneburg $R$, Lammert F, Rabe $C$ et al. Chromocolonoscopy detects more adenomas than white light colonoscopy or narrow band imaging colonoscopy in hereditary nonpolyposis colorectal cancer screening. Endoscopy 2009; 41: 316-322

62 Stoffel EM, Turgeon DK, Stockwell DH et al. Missed adenomas during colonoscopic surveillance in individuals with Lynch syndrome (hereditary nonpolyposis colorectal cancer). Cancer Prev Res (Phila) 2008; $1: 470-475$

63 East JE, Suzuki N, Stavrinidis M et al. Narrow band imaging for colonoscopic surveillance in hereditary non-polyposis colorectal cancer. Gut 2008; 57: 65-70

64 Bisschops $R$, Tejpar S, Willekens $H$ et al. I-scan detects more polyps in Lynch Syndrome (HNPCC) patients: a prospective controlled randomized back-to-back study. Gastrointest Endosc 2012; 75: AB330

65 Ramsoekh D, Haringsma J, Poley JW et al. A back-to-back comparison of white light video endoscopy with autofluorescence endoscopy for adenoma detection in high-risk subjects. Gut 2010; 59: 785 - 793

66 Boparai KS, van den Broek FJ, van Eeden S et al. Increased polyp detection using narrow band imaging compared with high resolution endoscopy in patients with hyperplastic polyposis syndrome. Endoscopy 2011; 43: 676-682

67 Boparai KS, van den Broek FJ, van Eeden S et al. Hyperplastic polyposis syndrome: a pilot study for the differentiation of polyps by using high-resolution endoscopy, autofluorescence imaging, and narrowband imaging. Gastrointest Endosc 2009; 70: 947-955

68 Soravia C, Berk T, Madlensky L et al. Genotype-phenotype correlations in attenuated adenomatous polyposis coli. Am J Hum Genet 1998; 62: $1290-1301$

69 Heiskanen I, Luostarinen T, Jarvinen HJ. Impact of screening examinations on survival in familial adenomatous polyposis. Scand J Gastroenterol 2000; 35: 1284-1287

70 Matsumoto T, Esaki M, Fujisawa R et al. Chromoendoscopy, narrowband imaging colonoscopy, and autofluorescence colonoscopy for detection of diminutive colorectal neoplasia in familial adenomatous polyposis. Dis Colon Rectum 2009; 52: 1160-1165

71 Friederich P, de Jong AE, Mathus-Vliegen LM et al. Risk of developing adenomas and carcinomas in the ileal pouch in patients with familial adenomatous polyposis. Clin Gastroenterol Hepatol 2008; 6: 1237 1242

72 Tajika M, Nakamura T, Nakahara $O$ et al. Prevalence of adenomas and carcinomas in the ileal pouch after proctocolectomy in patients with familial adenomatous polyposis. J Gastrointest Surg 2009; 13: 1266 1273

73 Van Assche G, Dignass A, Bokemeyer B et al. Second European evidence-based consensus on the diagnosis and management of ulcerative colitis part 3: special situations. J Crohns Colitis 2013; 7: 1-33

74 Rutter MD, Saunders BP, Wilkinson KH et al. Thirty-year analysis of a colonoscopic surveillance program for neoplasia in ulcerative colitis. Gastroenterology 2006; 130: 1030-1038

75 Watanabe K, Sogawa M, Yamagami H et al. Endoscopic differential diagnosis between ulcerative colitis-associated neoplasia and sporadic neoplasia in surveillance colonoscopy using narrow band imaging. Dig Endosc 2011; 23: 01143-149

76 Hurlstone DP, Sanders DS, Atkinson R et al. Endoscopic mucosal resection for flat neoplasia in chronic ulcerative colitis: can we change the endoscopic management paradigm? Gut 2007; 56: 838-846

77 Kiesslich R, Fritsch J, Holtmann $M$ et al. Methylene blue-aided chromoendoscopy for the detection of intraepithelial neoplasia and colon cancer in ulcerative colitis. Gastroenterology 2003; 124: 880-888

78 Kiesslich R, Goetz M, Lammersdorf K et al. Chromoscopy-guided endomicroscopy increases the diagnostic yield of intraepithelial neoplasia in ulcerative colitis. Gastroenterology 2007; 132: 874-882

79 Subramanian V, Mannath J, Ragunath K et al. Meta-analysis: the diagnostic yield of chromoendoscopy for detecting dysplasia in patients with colonic inflammatory bowel disease. Aliment Pharmacol Ther 2011; 33: 304-312

80 Hlavaty T, Huorka M, Koller T et al. Colorectal cancer screening in patients with ulcerative and Crohn's colitis with use of colonoscopy, chromoendoscopy and confocal endomicroscopy. Eur J Gastroenterol Hepatol 2011; 23: 680-689

81 Gunther $U$, Kusch D, Heller F et al. Surveillance colonoscopy in patients with inflammatory bowel disease: comparison of random biopsy vs. targeted biopsy protocols. Int J Colorectal Dis 2011; 26: 667 -672

82 Hurlstone DP, Sanders DS, Lobo AJ et al. Indigo carmine-assisted highmagnification chromoscopic colonoscopy for the detection and characterisation of intraepithelial neoplasia in ulcerative colitis: a prospective evaluation. Endoscopy 2005; 37: 1186-1192

83 Matsumoto T, Nakamura S, Jo Y et al. Chromoscopy might improve diagnostic accuracy in cancer surveillance for ulcerative colitis. Am J Gastroenterol 2003; 98: 1827-1833

84 Rutter MD, Saunders BP, Schofield G et al. Pancolonic indigo carmine dye spraying for the detection of dysplasia in ulcerative colitis. Gut 2004; 53: 256-260

85 Marion JF, Waye JD, Present DH et al. Chromoendoscopy-targeted biopsies are superior to standard colonoscopic surveillance for detecting dysplasia in inflammatory bowel disease patients: a prospective endoscopic trial. Am J Gastroenterol 2008; 103: 2342 - 2349

86 Eaden JA, Ward BA, Mayberry JF. How gastroenterologists screen for colonic cancer in ulcerative colitis: an analysis of performance. Gastrointest Endosc 2000; 51: 123-128

87 Olliver JR, Wild CP, Sahay P et al. Chromoendoscopy with methylene blue and associated DNA damage in Barrett's oesophagus. Lancet 2003; 362: 373-374

88 Elsadani NN, East JE, Walters JR. New 2010 British Society of Gastroenterology colitis surveillance guidelines: costs and surveillance intervals. Gut 2011; 60: 282-283

89 Kiesslich R, Neurath MF. Surveillance colonoscopy in ulcerative colitis: magnifying chromoendoscopy in the spotlight. Gut 2004; 53: 165 167

90 Cairns SR, Scholefield JH, Steele RJ et al. Guidelines for colorectal cancer screening and surveillance in moderate and high risk groups (update from 2002). Gut 2010; 59: 666-689

91 Annese V, Daperno M, Rutter MD et al. European evidence based consensus for endoscopy in inflammatory bowel disease. J Crohns Colitis 2013; 7: $982-1018$

92 Ignjatovic A, East JE, Subramanian $V$ et al. Narrow band imaging for detection of dysplasia in colitis: a randomized controlled trial. Am J Gastroenterol 2012; 107: 885-890 
93 Dekker E, van den Broek FJ, Reitsma JB et al. Narrow-band imaging compared with conventional colonoscopy for the detection of dysplasia in patients with longstanding ulcerative colitis. Endoscopy 2007; 39: 216-221

94 van den Broek FJ, Fockens P, van Eeden S et al. Endoscopic tri-modal imaging for surveillance in ulcerative colitis: randomised comparison of high-resolution endoscopy and autofluorescence imaging for neoplasia detection; and evaluation of narrow-band imaging for classification of lesions. Gut 2008; 57: $1083-1089$

95 Pellise M, Lopez-Ceron M, Rodriguez de Miguel C et al. Narrow-band imaging as an alternative to chromoendoscopy for the detection of dysplasia in long-standing inflammatory bowel disease: a prospective, randomized, crossover study. Gastrointest Endosc 2011; 74: $840-848$

96 Bisschops R, Bessissow T, Baert FJ et al. Chromoendoscopy versus narrow band imaging in ulcerative colitis: a prospective randomized controlled trial. Gastrointest Endosc 2012; 75: AB148

97 Matsumoto T, Nakamura S, Moriyama T et al. Autofluorescence imaging colonoscopy for the detection of dysplastic lesions in ulcerative colitis: a pilot study. Colorectal Dis 2010; 12: e291 - e297

98 van den Broek FJ, Fockens P, van Eeden S et al. Narrow-band imaging versus high-definition endoscopy for the diagnosis of neoplasia in ulcerative colitis. Endoscopy 2011; 43: 108-115

99 Matsumoto T, Kudo T, Jo Y et al. Magnifying colonoscopy with narrow band imaging system for the diagnosis of dysplasia in ulcerative colitis: a pilot study. Gastrointest Endosc 2007; 66: 957-965

100 East JE, Suzuki N, von Herbay A et al. Narrow band imaging with magnification for dysplasia detection and pit pattern assessment in ulcerative colitis surveillance: a case with multiple dysplasia associated lesions or masses. Gut 2006; 55: $1432-1435$

101 Regula J, Rupinski M, Kraszewska E et al. Colonoscopy in colorectalcancer screening for detection of advanced neoplasia. $\mathrm{N}$ Engl J Med 2006; 355: 1863 - 1872

102 Gschwantler M, Kriwanek S, Langner E et al. High-grade dysplasia and invasive carcinoma in colorectal adenomas: a multivariate analysis of the impact of adenoma and patient characteristics. Eur J Gastroenterol Hepatol 2002; 14: 183-188

103 Ignjatovic A, East JE, Suzuki $N$ et al. Optical diagnosis of small colorectal polyps at routine colonoscopy (Detect InSpect ChAracterise Resect and Discard; DISCARD trial): a prospective cohort study. Lancet Oncol 2009; 10: 1171 - 1178

104 Kiesslich R, von Bergh M, Hahn M et al. Chromoendoscopy with indigocarmine improves the detection of adenomatous and nonadenomatous lesions in the colon. Endoscopy 2001; 33: 1001-1006

105 Ignjatovic A, East JE, Guenther T et al. What is the most reliable imaging modality for small colonic polyp characterization? Study of white-light, autofluorescence, and narrow-band imaging Endoscopy 2011; 43: 94-99

106 Rex DK, Kahi C, O'Brien M et al. The American Society for Gastrointestinal Endoscopy PIVI (Preservation and Incorporation of Valuable Endoscopic Innovations) on real-time endoscopic assessment of the histology of diminutive colorectal polyps. Gastrointest Endosc 2011; 73: $419-422$

107 Granqvist S, Gabrielsson N, Sundelin P. Diminutive colonic polyps clinical significance and management. Endoscopy 1979; 11: 36-42

108 Church JM, Fazio VW, Jones IT. Small colorectal polyps. Are they worth treating? Dis Colon Rectum 1988; 31: 50-53

109 O'Brien MJ, Winawer SJ, Zauber AG et al. The National Polyp Study. Patient and polyp characteristics associated with high-grade dysplasia in colorectal adenomas. Gastroenterology 1990; 98: 371-379

110 Weston AP, Campbell DR. Diminutive colonic polyps: histopathology, spatial distribution, concomitant significant lesions, and treatment complications. Am J Gastroenterol 1995; 90: 24-28

111 Read TE, Read JD, Butterly LF. Importance of adenomas $5 \mathrm{~mm}$ or less in diameter that are detected by sigmoidoscopy. NEJM 1997; 336: 8-12

112 Nusko G, Mansmann U, Altendorf-Hofmann A et al. Risk of invasive carcinoma in colorectal adenomas assessed by size and site. Int J Colorect Dis 1997; 12: 267-271

113 Aldridge AJ, Simson JN. Histological assessment of colorectal adenomas by size. Are polyps less than $10 \mathrm{~mm}$ in size clinically important? Eur J Surg 2001; 167: 777-781

114 Pickhardt PJ, Choi JR, Hwang I et al. Computed tomographic virtual colonoscopy to screen for colorectal neoplasia in asymptomatic adults. NEJM 2003; 349: 2191 - 2200
115 Church JM. Clinical significance of small colorectal polyps. Dis Colon Rectum 2004; 47: 481-485

116 O'Brien MJ, Winawer SJ, Zauber AG et al. Flat adenomas in the National Polyp Study: is there increased risk for high-grade dysplasia initially or during surveillance? Clin Gastroenterol Hepatol 2004; 2: 905 - 911

117 Souques M, Lassalle M, Guldner L et al. Colorectal polyps and cancers diagnosed by pathologists in Ile de France region. Crisapif-Petri Study. Gastroenterol Clin Biol 2006; 30: 587-593

118 Chen SC, Mouchli A, Chadalawada V et al. Histopathology of small polyps removed in the videoendoscopic era. Gastrointest Endosc 2006; 63: AB199

119 Butterly LF, Chase MP, Pohl H et al. Prevalence of clinically important histology in small adenomas. Clin Gastroenterol Hepatol 2006; 4: $343-348$

120 Kim DH, Pickhardt PJ, Taylor AJ et al. CT colonography versus colonoscopy for the detection of advanced neoplasia. NEJM 2007; 357: $1403-1412$

121 Yoo TW, Park DI, Kim YH et al. Clinical significance of small colorectal adenoma less than $10 \mathrm{~mm}$ : the KASID study. Hepatogastroenterology 2007; 54: $418-421$

122 Lieberman D, Moravec M, Holub J et al. Polyp size and advanced histology in patients undergoing colonoscopy screening: implications for CT colonography. Gastroenterology 2008; 135: 1100-1105

123 Rex DK, Overhiser AJ, Chen SC et al. Estimation of impact of American College of Radiology recommendations on CT colonography reporting for resection of high-risk adenoma findings. American J Gastroenterol 2009; 104: 149-153

124 Graser A, Stieber P, Nagel D et al. Comparison of CT colonography, colonoscopy, sigmoidoscopy and faecal occult blood tests for the detection of advanced adenoma in an average risk population. Gut 2009; 58: $241-248$

125 Bretagne JF, Manfredi S, Piette $C$ et al. Yield of high-grade dysplasia based on polyp size detected at colonoscopy: a series of 2295 examinations following a positive fecal occult blood test in a populationbased study. Dis Colon Rectum 2010; 53: 339-345

126 Denis B, Bottlaender J, Weiss AM et al. Some diminutive colorectal polyps can be removed and discarded without pathological examination. Endoscopy 2011; 43: 81-86

127 Chaput $U$, Alberto SF, Terris B et al. Risk factors for advanced adenomas amongst small and diminutive colorectal polyps: a prospective monocenter study. Dig Liver Dis 2011; 43: 609-612

128 Repici A, Hassan C, Vitetta $E$ et al. Safety of cold polypectomy for $<10 \mathrm{~mm}$ polyps at colonoscopy: a prospective multicenter study. Endoscopy 2012; 44: 27-31

129 Tsai FC, Strum WB. Prevalence of advanced adenomas in small and diminutive colon polyps using direct measurement of size. Dig Dis Sci 2011; 56: 2384-2388

130 Shapiro R, Ben-Horin S, Bar-Meir S et al. The risk of advanced histology in small-sized colonic polyps: are non-invasive colonic imaging modalities good enough? Int J Colorect Dis 2012; 27: 1071 - 1075

131 Kolligs FT, Crispin A, Graser A et al. Risk factors for advanced neoplasia within subcentimetric polyps: implications for diagnostic imaging. Gut 2012; 62: 863-870 doi: DOI 10.1136/gutjnl-2011-300111 Epub 2012 Apr 23

132 Gupta N, Bansal A, Rao D et al. Prevalence of advanced histological features in diminutive and small colon polyps. Gastrointest Endosc 2012; 75: $1022-1030$

133 Terry MB, Neugut AI, Bostick RM et al. Reliability in the classification of advanced colorectal adenomas. Cancer Epidemiol Biomarkers Prev 2002; 11: 660-663

134 Costantini M, Sciallero S, Giannini A et al. Interobserver agreement in the histologic diagnosis of colorectal polyps. the experience of the multicenter adenoma colorectal study (SMAC). J Clin Epidemiol 2003; 56: 209-214

135 Lasisi F, Mouchli A, Riddell $R$ et al. Agreement in interpreting villous elements and dysplasia in adenomas less than one centimetre in size. Dig Liver Dis 2013; 45: 1049-1055

136 Atkin WS, Valori R, Kuipers EJ et al. European guidelines for quality assurance in colorectal cancer screening and diagnosis. First EditionColonoscopic surveillance following adenoma removal. Endoscopy 2012; 44: E151 - 163

137 Lieberman DA, Rex DK, Winawer SJ et al. Guidelines for colonoscopy surveillance after screening and polypectomy: a consensus update by the US Multi-Society Task Force on Colorectal Cancer. Gastroenterology 2012; 143: 844-857 
138 Hassan C, Quintero E, Dumonceau JM et al. Post-polypectomy colonoscopy surveillance: European Society of Gastrointestinal Endoscopy (ESGE) Guideline. Endoscopy 2013; 45: 842 - 864

139 Endoscopic Classification Review Group. Update on the Paris classification of superficial neoplastic lesions in the digestive tract. Endoscopy $2005 ; 37: 570-578$

140 Longcroft-Wheaton G, Brown J, Cowlishaw D et al. High-definition vs. standard-definition colonoscopy in the characterization of small colonic polyps: results from a randomized trial. Endoscopy 2012; 44: 905-910

141 McGill SK, Evangelou E, Ioannidis JP et al. Narrow band imaging to differentiate neoplastic and non-neoplastic colorectal polyps in real time: a meta-analysis of diagnostic operating characteristics. Gut 2013; 62: 1704-1713 DOI 10.1136/gutjnl-2012-303965

142 Togashi K, Osawa H, Koinuma K et al. A comparison of conventional endoscopy, chromoendoscopy, and the optimal-band imaging system for the differentiation of neoplastic and non-neoplastic colonic polyps. Gastrointest Endosc 2009; 69: 734-741

143 Ladabaum U, Fioritto A, Mitani A et al. Real-time optical biopsy of colon polyps with narrow band imaging in community practice does not yet meet key thresholds for clinical decisions. Gastroenterology 2013; 144: 81 - 91

144 Paggi S, Rondonotti E, Amato A et al. Resect and discard strategy in clinical practice: a prospective cohort study. Endoscopy 2012; 44: 899-904

145 Schachschal G, Mayr M, Treszl A et al. Endoscopic versus histological characterisation of polyps during screening colonoscopy. Gut 28. 06 2013: DOI 10.1136/gutjnl-2013-304562

146 Masci E, Mangiavillano B, Crosta $C$ et al. Interobserver agreement among endoscopists on evaluation of polypoid colorectal lesions visualized with the Pentax i-Scan technique. Dig Liver Dis 2013; 45: 207-210

147 Pigo F, Bertani H, Manno $M$ et al. i-Scan high-definition white light endoscopy and colorectal polyps: prediction of histology, interobserver and intraobserver agreement. Int J Colorectal Dis 2013; 28: 399_406

148 van den Broek FJ, van Soest EJ, Naber AH et al. Combining autofluorescence imaging and narrow-band imaging for the differentiation of adenomas from non-neoplastic colonic polyps among experienced and non-experienced endoscopists. Am J Gastroenterol 2009; 104: $1498-1507$

149 Rastogi A, Pondugula K, Bansal A et al. Recognition of surface mucosal and vascular patterns of colon polyps by using narrow-band imaging: interobserver and intraobserver agreement and prediction of polyp histology. Gastrointest Endosc 2009; 69: 716-22

150 Huang $Q$ Fukami $N$, Kashida $H$ et al. Interobserver and intra-observer consistency in the endoscopic assessment of colonic pit patterns. Gastrointest Endosc 2004; 60: 520-526

151 East JE, Suzuki N, Saunders BP. Comparison of magnified pit pattern interpretation with narrow band imaging versus chromoendoscopy for diminutive colonic polyps: a pilot study. Gastrointest Endosc 2007: 66: $310-316$

152 Sato R, Fujiya $M$, Watari $J$ et al. The diagnostic accuracy of high-resolution endoscopy, autofluorescence imaging and narrow-band imaging for differentially diagnosing colon adenoma. Endoscopy 2011; 43: $862-868$

153 Rogart JN, Jain D, Siddiqui UD et al. Narrow-band imaging without high magnification to differentiate polyps during real-time colonoscopy: improvement with experience. Gastrointest Endosc 2008; 68: $1136-1145$

154 East JE, Suzuki N, Bassett $P$ et al. Narrow band imaging with magnification for the characterization of small and diminutive colonic polyps: pit pattern and vascular pattern intensity. Endoscopy 2008; 40: $811-817$

155 Ignjatovic A, Thomas-Gibson S, East JE et al. Development and validation of a training module on the use of narrow-band imaging in differentiation of small adenomas from hyperplastic colorectal polyps. Gastrointest Endosc 2011; 73: 128-133

156 Raghavendra $M$, Hewett DG, Rex DK. Differentiating adenomas from hyperplastic colorectal polyps: narrow-band imaging can be learned in 20 minutes. Gastrointest Endosc 2010; 72: 572 - 576

157 Rastogi A, Rao DS, Gupta N et al. Impact of a computer-based teaching module on characterization of diminutive colon polyps by using narrow-band imaging by non-experts in academic and community prac- tice: a video-based study. Gastrointest Endosc 07. 09 2013: DOI 10.1016/j.gie.2013.07.032 [Epub ahead of print]

158 Higashi R, Uraoka T, Kato J et al. Diagnostic accuracy of narrow-band imaging and pit pattern analysis significantly improved for less-experienced endoscopists after an expanded training program. Gastrointest Endosc 2010; 72: 127-135

159 Hewett DG, Kaltenbach T, Sano Yet al. Validation of a simple classification system for endoscopic diagnosis of small colorectal polyps using narrow-band imaging. Gastroenterology 2012; 143: 599-607.e1

160 Kumar S, Fioritto A, Mitani A et al. Optical biopsy of sessile serrated adenomas: do these lesions resemble hyperplastic polyps under narrow-band imaging? Gastrointest Endosc 2013; 78: 902-909 DOI 10.1016/j.gie.2013.06.004

161 Varnavas A, Ignjatovic A, Bharath A et al. Classification of colon images using the magnitude of orientation dominance. Proceedings of the 5th UKRI PG Conference in Biomedical Engineering and Medical Physics 2009; $1: 13-14$

162 TischendorfJJ, Gross S, Winograd R et al. Computer-aided classification of colorectal polyps based on vascular patterns: a pilot study. Endoscopy 2010; 42: 203-207

163 Takemura Y, Yoshida S, Tanaka S et al. Computer-aided system for predicting the histology of colorectal tumors by using narrow-band imaging magnifying colonoscopy (with video). Gastrointest Endosc 2012; 75: 179-185

164 Gross S, Trautwein C, Behrens A et al. Computer-based classification of small colorectal polyps by using narrow-band imaging with optical magnification. Gastrointest Endosc 2011; 74: 1354-1359

165 Gupta N, Bansal A, Rao D et al. Accuracy of in vivo optical diagnosis of colon polyp histology by narrow-band imaging in predicting colonoscopy surveillance intervals. Gastrointest Endosc 2012; 75: 494 502

166 Longcroft-Wheaton GR, Higgins B, Bhandari P. Flexible spectral imaging color enhancement and indigo carmine in neoplasia diagnosis during colonoscopy: a large prospective UK series. Eur J Gastroenterol Hepatol 2011; 23: 903-911

167 Hassan C, Pickhardt PJ, Rex DK. A resect and discard strategy would improve cost-effectiveness of colorectal cancer screening. Clin Gastroenterol Hepatol 2010; 8: 865-869, 869e1-e3

168 Valori R, Rey JF, Atkin WS et al. European guidelines for quality assurance in colorectal cancer screening and diagnosis. First edition-Quality assurance in endoscopy in colorectal cancer screening and diagnosis. Endoscopy 2012; 44: E88-105

169 Steele RJ, Pox C, Kuipers EJ et al. European guidelines for quality assurance in colorectal cancer screening and diagnosis. First edition-Management of lesions detected in colorectal cancer screening. Endoscopy 2012; 44: E140 - 50

170 Watanabe T, Itabashi M, Shimada $Y$ et al. Japanese Society for Cancer of the Colon and Rectum (JSCCR) guidelines 2010 for the treatment of colorectal cancer. Int J Clin Oncol 2012; 17: 1-29

171 Nakadoi K, Tanaka S, Kanao H et al. Management of T1 colorectal carcinoma with special reference to criteria for curative endoscopic resection. J Gastroenterol Hepatol 2012; 27: 1057-1062

172 Kudo S, Rubio CA, Teixeira CR et al. Pit pattern in colorectal neoplasia: endoscopic magnifying view. Endoscopy 2001; 33: 367-373

173 Hirata M, Tanaka S, Oka S et al. Evaluation of microvessels in colorectal tumors by narrow band imaging magnification. Gastrointest Endosc 2007; 66: 945-952

174 Fujii T, Hasegawa RT, Saitoh Y et al. Chromoscopy during colonoscopy. Endoscopy 2001; 33: $1036-1041$

175 Nagata S, Tanaka S, Haruma K et al. Pit pattern diagnosis of early colorectal carcinoma by magnifying colonoscopy: clinical and histological implications. Int J Oncol 2000; 16: 927 - 934

176 Kudo S, Lambert R, Allen JI et al. Nonpolypoid neoplastic lesions of the colorectal mucosa. Gastrointest Endosc 2008; 68: 3-S47

177 Bianco MA, Rotondano G, Marmo R et al. Predictive value of magnification chromoendoscopy for diagnosing invasive neoplasia in nonpolypoid colorectal lesions and stratifying patients for endoscopic resection or surgery. Endoscopy 2006; 38: 470-476

178 Kanao H, Tanaka S, Oka S et al. Narrow-band imaging magnification predicts the histology and invasion depth of colorectal tumors. Gastrointest Endosc 2009; 69: 631 -636

179 Wada Y, Kudo SE, Kashida H et al. Diagnosis of colorectal lesions with the magnifying narrow-band imaging system. Gastrointest Endosc 2009; 70: $522-531$ 
180 Matsumoto K, Nagahara A, Terai T et al. Evaluation of new subclassification of type $\mathrm{V}(\mathrm{I})$ pit pattern for determining the depth and type of invasion of colorectal neoplasm. J Gastroenterol 2011; 46: 31-38

181 Kanao H, Tanaka S, Oka S et al. Clinical significance of type V(I) pit pattern subclassification in determining the depth of invasion of colorectal neoplasms. World J Gastroenterol 2008; 14: 211 -217

182 Kobayashi N, Saito Y, Sano Y et al. Determining the treatment strategy for colorectal neoplastic lesions: endoscopic assessment or the nonlifting sign for diagnosing invasion depth? Endoscopy 2007; 39: $701-705$

183 Saitoh Y, Obara T, Watari J et al. Invasion depth diagnosis of depressed type early colorectal cancers by combined use of videoendoscopy and chromoendoscopy. Gastrointest Endosc 1998; 48: 362 - 370

184 Matsuda T, Fujii T, Saito $Y$ et al. Efficacy of the invasive/non-invasive pattern by magnifying chromoendoscopy to estimate the depth of invasion of early colorectal neoplasms. Am J Gastroenterol 2008; 103: $2700-2706$

185 Hayashi N, Tanaka S, Hewett DG et al. Endoscopic prediction of deep submucosal invasive carcinoma: validation of the narrow-band imaging international colorectal endoscopic (NICE) classification. Gastrointest Endosc 2013; 78: 625 - 632 doi: DOI 10.1016/j.gie.2013.04.185

186 Tsuda S, Veress B, Toth E et al. Flat and depressed colorectal tumours in a southern Swedish population: a prospective chromoendoscopic and histopathological study. Gut 2002; 51: 550-555

187 Rembacken BJ, Fujii T, Cairns A et al. Flat and depressed colonic neoplasms: a prospective study of 1000 colonoscopies in the UK. Lancet 2000; 355: 1211 - 1214

188 Hurlstone DP, Cross SS, Adam I et al. A prospective clinicopathological and endoscopic evaluation of flat and depressed colorectal lesions in the United Kingdom. Am J Gastroenterol 2003; 98: 2543-2549

189 Soetikno RM, Kaltenbach T, Rouse RV et al. Prevalence of nonpolypoid (flat and depressed) colorectal neoplasms in asymptomatic and symptomatic adults. JAMA 2008; 299: 1027-1035

190 Diebold MD, Samalin E, Merle C et al. Colonic flat neoplasia: frequency and concordance between endoscopic appearance and histological diagnosis in a French prospective series. Am J Gastroenterol 2004; 99: $1795-1800$

191 Rotondano G, Bianco MA, Buffoli $F$ et al. The Cooperative Italian FLIN Study Group: prevalence and clinico-pathological features of colorectal laterally spreading tumors. Endoscopy 2011; 43: 856-861

192 Bianco MA, Cipolletta L, Rotondano $G$ et al. Prevalence of nonpolypoid colorectal neoplasia: an Italian multicenter observational study. Endoscopy 2010; 42: 279-285
193 Robertson DJ, Greenberg ER, Beach M et al. Colorectal cancer in patients under close colonoscopic surveillance. Gastroenterology 2005; 129: 34-41

194 Pabby A, Schoen RE, Weissfeld JL et al. Analysis of colorectal cancer occurrence during surveillance colonoscopy in the dietary Polyp Prevention Trial. Gastrointest Endosc 2005; 61: 385 - 391

195 Pohl H, Srivastava A, Bensen SP et al. Incomplete polyp resection during colonoscopy - results of the complete adenoma resection (CARE) study. Gastroenterology 2013; 144: $74-80$ e1

196 Hurlstone DP, Cross SS, Brown S et al. A prospective evaluation of highmagnification chromoscopic colonoscopy in predicting completeness of EMR. Gastrointest Endosc 2004; 59: 642 - 650

197 Hurlstone DP, Cross SS, Drew K. An evaluation of colorectal endoscopic mucosal resection using high-magnification chromoscopic colonoscopy: a prospective study of 1000 colonoscopies. Endoscopy 2004; 36: $491-498$

198 Moss A, Bourke MJ, Williams SJ et al. Endoscopic mucosal resection outcomes and prediction of submucosal cancer from advanced colonic mucosal neoplasia. Gastroenterology 2011; 140: 1909-1918

199 Buchner AM, Guarner-Argente C, Ginsberg GG. Outcomes of EMR of defiant colorectal lesions directed to an endoscopy referral center. Gastrointest Endosc 2012; 76: 255-263

200 Cipolletta L, Bianco MA, Garofano ML et al. Can magnification endoscopy detect residual adenoma after piecemeal resection of large sessile colorectal lesions to guide subsequent treatment? A prospective single-center study Dis Colon Rectum 2009; 52: 1774-1779

201 Munakata A, Uno Y. Colonoscopic polypectomy with local injection of methylene blue. Tohoku J Exp Med 1994; 173: 377-382

202 Khashab M, Eid E, Rusche M et al. Incidence and predictors of "late" recurrences after endoscopic piecemeal resection of large sessile adenomas. Gastrointest Endosc 2009; 70: 344-349

203 Shahid MW, Buchner AM, Coron E et al. Diagnostic accuracy of probebased confocal laser endomicroscopy in detecting residual colorectal neoplasia after EMR: a prospective study. Gastrointest Endosc 2012 75: $525-533$

204 Rogart JN, Aslanian HR, Siddiqui UD. Narrow band imaging to detect residual or recurrent neoplastic tissue during surveillance endoscopy. Dig Dis Sci 2011; 56: $472-478$

205 Higaki S, Hashimoto S, Harada $\mathrm{K}$ et al. Long-term follow-up of large flat colorectal tumors resected endoscopically. Endoscopy 2003; 35 : $845-849$

206 Hurlstone DP, Sanders DS, Cross SS et al. Colonoscopic resection of lateral spreading tumours: a prospective analysis of endoscopic mucosal resection. Gut 2004; 53: 1334-1339

\section{Appendix e1 - e8}

online content viewable at: www.thieme-connect.de 
Appendix e1 Chapter structure, task forces and key questions.

General remark: Techniques still under development such as confocal, endocytoscopy, optical coherence tomography are not be included in this Guideline.

\section{Task force I. Detection of colorectal neoplasia in average risk population}

- What is the efficacy of conventional chromoendoscopy compared with white-light endoscopy for the detection of colorectal neoplasia in an average-risk population?

- What is the additional time and cost associated with the use of conventional chromoendoscopy?

- Is this method applicable to an average-risk population?

- What is the efficacy of virtual chromoendoscopy (NBI, FICE, i-SCAN) compared with white-light endoscopy for the detection of colorectal neoplasia in an average-risk population?

- What is the additional time and cost associated with the use of virtual chromoendoscopy?

- What is the efficacy of autofluorescence imaging compared with white-light endoscopy for the detection of colorectal neoplasia in an average-risk population?

- What is the additional time and cost associated with the use of autofluorescence imaging?

- What is the efficacy of high definition white-light endoscopy compared with standard white-light endoscopy for the detection of colorectal neoplasia in an average-risk population?

- What is the additional cost associated with the use of high definition endoscopy?

- What is the efficacy of white light endoscopy plus add-on devices (e. g. third eye retroscope [TER], cap-assisted colonoscopy) compared with white-light endoscopy only for the detection of colorectal neoplasia in an average-risk population?

- What is the additional time and cost associated with the use of add-on devices?

Task force II. Detection of colorectal neoplasia in hereditary syndromes including Lynch syndrome, familial adenomatous polyposis (FAP), attenuated FAP and MUTYH-associated polyposis (MAP), serrated polyposis and Peutz-Jeghers syndrome

- What is the efficacy of virtual chromoendoscopy (NBI, FICE, i-SCAN) compared with white-light endoscopy for the detection of colorectal neoplasia in hereditary syndromes?

- What is the additional time and cost associated with the use of virtual chromoendoscopy?

- What is the efficacy of conventional chromoendoscopy compared with white-light endoscopy for the detection of colorectal neoplasia in hereditary syndromes?

- What is the additional time and cost associated with the use of conventional chromoendoscopy? Is this method applicable to a high risk population?

- What is the efficacy of other advanced endoscopic techniques for the detection of colorectal neoplasia in hereditary syndromes?

Task force III. Detection and differentiation of colorectal neoplasia in inflammatory bowel disease (IBD)

- What is the efficacy of conventional pan-chromoendoscopy compared with four-quadrant random biopsies for the detection of colorectal neoplasia in IBD?

- What is the time and number of biopsies needed to perform pan-chromoendoscopy compared with four-quadrant random biopsies? What is the preferable type, amount, and concentration of the stain to be used?

- Should it be recommended for surveillance in all patients with long-standing IBD?

- What is the efficacy of virtual chromoendoscopy compared with four-quadrant random biopsies or conventional panchromoendoscopy for the detection of colorectal neoplasia in IBD?

- What is the efficacy of other advanced endoscopic techniques for the detection of colorectal neoplasia in IBD?

- What is the efficacy of pan-chromoendoscopy/virtual chromoendoscopy compared with white-light endoscopy for differentiation of colorectal neoplasia in IBD?

- Is there a reduction in the number of biopsies if these techniques are combined?

Task force IV. Differentiation between neoplastic and non-neoplastic small colorectal polyps

- What is the efficacy of advanced endoscopic imaging compared with white-light endoscopy for differentiation between neoplastic and non-neoplastic small colorectal polyps?

- What are the implications of a resect and discard strategy for post-polypectomy follow-up and cost- effectiveness?

- What is the prevalence of advanced colorectal neoplasia in colorectal polyps less than $6 \mathrm{~mm}(10 \mathrm{~mm})$ ?

- What is the interobserver variability in differentiation between neoplastic and non-neoplastic colorectal polyps?

- Is there a training system for differentiation between neoplastic and non-neoplastic colorectal polyps?

- What kind of documentation is needed for the resected and discarded polyps?

\section{- Role of computer-aided characterization}

Task force V. Advanced endoscopic imaging aided treatment of neoplasia

- What is the efficacy of advanced endoscopic imaging for differentiation of malignant and non-malignant colorectal neoplasia?

- What is the efficacy of advanced endoscopic imaging for determining the depth of invasion in early colorectal cancer?

- How does it compare with submucosal injection?

- What is the efficacy of advanced endoscopic imaging for demarcating the margins of EMR/ESD?

- What is the efficacy of advanced endoscopic imaging for the detection of post-polypectomy/post-EMR scars and residual/recurrent colorectal neoplasia?
Task forces (leaders in bold)

Ana Ignjatovic

\section{Jürgen Poh}

Maria Pellisé

Arthur Hoffman

Jean-Marc Dumonceau

\section{Maria Pellisé}

Gaius Longcroft-Wheaton

James East

Evelien Dekker

\section{Raf Bisschops}

\section{Michał F. Kamińsk}

\section{Raf Bisschops}

Arthur Hoffman

Evelien Dekker

Gaius Longcroft-Wheaton

Denis Heresbach

Ana Ignjatovic

Ana Ignjatovic

James East

Cesare Hassan

\section{Cesare Hassan}

Ana Ignjatovic

Michał F. Kamiński

NBI, narrow band imaging; FICE, Fujinon Intelligent Color Enhancement; EMR, endoscopic mucosal resection; ESD, endoscopic submucosal dissection 
Appendix e2 a Levels of evidence according to the Grading of Recommendations Assessment, Development and Evaluation (GRADE) system [8].

$\begin{array}{ll}\text { Evidence level } & \begin{array}{l}\text { One or more well-designed and well-executed randomized controlled trials (RCTs) that yield consistent and directly applicable re- } \\ \text { sults. This also means that further research is very unlikely to change our confidence in the estimate of effect. }\end{array} \\ \text { Moderate quality } & \begin{array}{l}\text { RCTs with important limitations (i. e. biased assessment of the treatment effect, large loss to follow-up, lack of blinding, unexplained } \\ \text { heterogeneity), indirect evidence originating from similar (but not identical) populations of interest, and RCTs with a very small } \\ \text { number of participants or observed events. In addition, evidence from well-designed controlled trials without randomization, well- } \\ \text { designed cohort or case - control analytic studies, and multiple time series with or without intervention are in this category. It also } \\ \text { means that further research will probably have an important effect on our confidence in the estimate of effect and may change the } \\ \text { estimate. }\end{array} \\ \begin{array}{l}\text { Observational studies would typically be rated as low quality because of the risk for bias. }{ }^{1} \text { It also means that further research is very } \\ \text { likely to have an important effect on our confidence in the estimate of effect and will probably change the estimate. }\end{array} \\ \text { Very low quality }{ }^{2} & \begin{array}{l}\text { Evidence is conflicting, of poor quality, or lacking, and hence the balance of benefits and harms cannot be determined. Any estimate } \\ \text { of effect that is very uncertain as evidence is either unavailable or does not permit a conclusion. }\end{array}\end{array}$

${ }^{1}$ Quality of evidence based on observational studies may be rated as moderate or even high, depending on circumstances under which evidence is obtained from observational studies. Factors that may contribute to upgrading the quality of evidence include a large magnitude of the observed effect, a dose - response association, or the presence of an observed effect when all plausible confounders would decrease the observed effect.

2 Insufficient evidence to determine for or against routinely providing a service.

Appendix e2 b Strength of recommendations according to the Grading of Recommendations Assessment, Development and Evaluation (GRADE) system [8].

\section{Strength of recommendation}




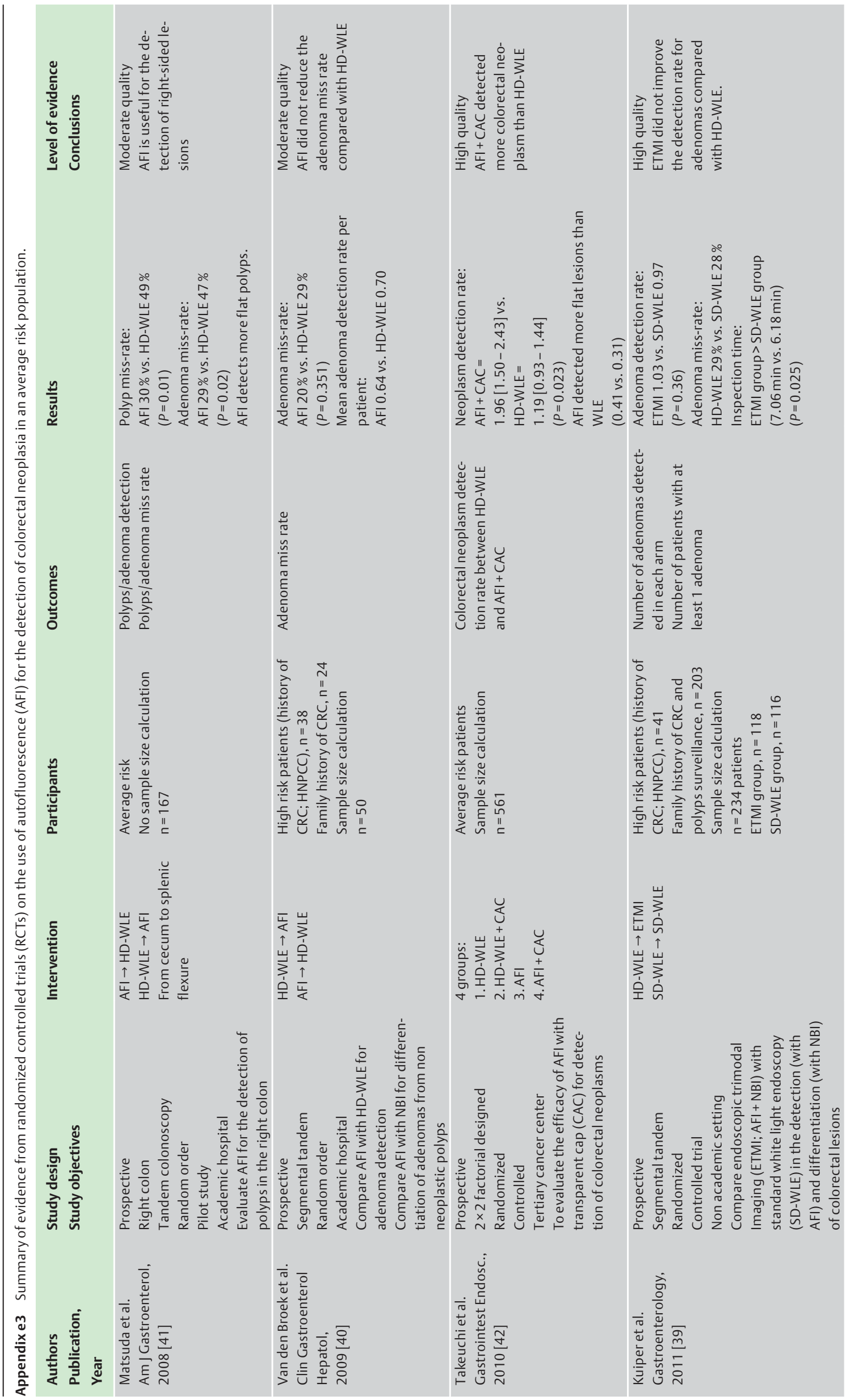


Appendix e4 Mean withdrawal time, number of polyps per patient and number of adenomas per patient in studies using conventional chromoendoscopy compared with standard definition or high definition white-light endoscopy (WLE) for colonoscopic surveillance in Lynch syndrome.

\begin{tabular}{|c|c|c|c|c|c|c|c|}
\hline \multirow[t]{2}{*}{ Study design } & \multirow[t]{2}{*}{ Patients, n } & \multicolumn{2}{|c|}{ Mean withdrawal time, min } & \multicolumn{2}{|c|}{$\begin{array}{l}\text { Mean number of polyps per } \\
\text { patient }\end{array}$} & \multicolumn{2}{|c|}{$\begin{array}{l}\text { Mean number of adenomas per } \\
\text { patient }\end{array}$} \\
\hline & & WLE & Chromoendoscopy & WLE & Chromoendoscopy & WLE & Chromoendoscopy \\
\hline \multicolumn{8}{|l|}{ Tandem, sequential ${ }^{1}$} \\
\hline Hurlstone et al. 2005 [59] & 25 & $14.8^{2}$ & 16 & 0.96 & 2.08 & 0.44 & 1.28 \\
\hline Lecomte et al. 2005 [60] & 33 & $\mathrm{n} / \mathrm{a}$ & 17 & 0.69 & 1.25 & 0.19 & 0.30 \\
\hline Huneberg et al. 2009 [61] & $47^{3}$ & 7.6 & 18.0 & 0.53 & 0.98 & 0.15 & 0.13 \\
\hline \multicolumn{8}{|c|}{ Tandem, randomized second examination ${ }^{4}$} \\
\hline Stoffel et al. 2008 [62] & 52 & 25.3 & 29.8 & 0.6 & 0.8 & 0.5 & 0.4 \\
\hline
\end{tabular}

1 Note: "chromoendoscopy" detection rates shown here represent the total number of lesions detected by rates WLE plus chromoendoscopy.

2 Includes time for saline lavage

${ }^{3}$ WLE-chromoendoscopy arm only

${ }^{4}$ Note: WLE rates here reflect standard WLE plus WLE with intensive inspection versus chromoendoscopy rates which are standard WLE plus chromoendoscopy as above

Appendix e5 Diagnostic yield of targeted and random biopsies in conventional chromoendoscopy surveillance of long-standing colitis.

\begin{tabular}{|c|c|c|c|c|c|c|}
\hline \multirow[t]{2}{*}{ Study } & \multirow[t]{2}{*}{ Colonoscopies, n } & \multicolumn{2}{|c|}{ Biopsies per procedure, $n$} & \multicolumn{3}{|c|}{ Neoplasia yield from biopsies } \\
\hline & & Targeted & $\begin{array}{l}\text { Targeted and } \\
\text { random }\end{array}$ & Targeted-only, $\mathbf{n}$ & $\begin{array}{l}\text { Targeted and } \\
\text { random, } \mathbf{n}\end{array}$ & $\begin{array}{l}\text { (Targeted-only/Target- } \\
\text { ed and random), \% }\end{array}$ \\
\hline Kiesslich et al. 2003 [77] & 84 & 14.2 & 42.2 & 35 & 35 & $100 \%$ \\
\hline Matsumoto et al. 2003 [83] & 117 & 1 & 7 & 25 & 28 & $89 \%$ \\
\hline Rutter et al. 2004 [84] & 100 & 1.1 & 30.1 & 7 & 7 & $100 \%$ \\
\hline Hurlstone et al. 2005 [82] & 350 & 1.8 & 38.8 & 49 & 69 & $71 \%$ \\
\hline Kiesslich et al. 2007 [78] & 80 & $3.9^{2}$ & 21.1 & 19 & 19 & $100 \%$ \\
\hline Marion et al. 2008 [85] & 102 & 1.3 & 33.3 & 20 & 23 & $87 \%$ \\
\hline Hlavaty et al. 2011 [80] & 45 & n.a. & 35.2 & 6 & 6 & $100 \%$ \\
\hline Gunther et al. 2011 [81] & 50 & 0.28 & 36.2 & 2 & 2 & $100 \%$ \\
\hline $\begin{array}{l}\text { Pooled } \\
\text { (Pancolonic-only chromo- } \\
\text { endoscopy values in par- } \\
\text { entheses) }\end{array}$ & $\begin{array}{l}928 \\
(578)\end{array}$ & $\begin{array}{c}1.3^{3} \\
\left(1.2^{3}\right)\end{array}$ & $\begin{array}{l}34.3^{3} \\
\left(33.3^{3}\right)\end{array}$ & $\begin{array}{l}163 \\
(114)\end{array}$ & $\begin{array}{l}189 \\
(120)\end{array}$ & $\begin{array}{r}86 \% \\
(95 \%)\end{array}$ \\
\hline
\end{tabular}

n.a., not available

${ }^{1}$ Non-pancolonic chromoendoscopy was used

2 Suspicious lesions were assessed additionally with endomicroscopy

3 Median 


\begin{tabular}{|c|c|c|c|c|c|c|c|c|}
\hline \multirow[t]{2}{*}{$\begin{array}{l}\text { First author } \\
\text { Year }\end{array}$} & \multirow[t]{2}{*}{$\begin{array}{l}\text { Number of patients } \\
\text { Baseline risk }\end{array}$} & \multirow[t]{2}{*}{ Lesions, number and type } & \multicolumn{3}{|c|}{$\begin{array}{l}\text { \% Tubulovillous or villous and/or } \\
\text { HGD, \% }\end{array}$} & \multicolumn{3}{|c|}{ Carcinoma ${ }^{1}$} \\
\hline & & & $\leq 5 \mathrm{~mm}$ & $6-10 \mathrm{~mm}$ & $>10 \mathrm{~mm}$ & $\leq 5 \mathrm{~mm}$ & $6-9 \mathrm{~mm}$ & $\geq 10 \mathrm{~mm}$ \\
\hline $\begin{array}{l}\text { Granqvist } \\
1979 \text { [107] }\end{array}$ & $\begin{array}{l}114 \text { patients } \\
\text { Risk unknown }\end{array}$ & $\begin{array}{l}300 \text { polyps } \\
111 \text { adenomas } \\
300 \text { polyps } \leq 4 \mathrm{~mm}\end{array}$ & $\begin{array}{l}0.3 \\
0.9\end{array}$ & n.a. & n.a. & - & n.a. & n.a. \\
\hline $\begin{array}{l}\text { Church } \\
1988[108]\end{array}$ & $\begin{array}{l}303 \text { patients } \\
\text { Risk increased } 73 \% \\
\text { Retrospective }\end{array}$ & $\begin{array}{l}766 \text { polyps } \\
458 \text { adenomas } \\
766 \text { polyps } \leq 5 \mathrm{~mm}\end{array}$ & $\begin{array}{l}0.5 \\
0.9\end{array}$ & n.a. & n.a. & - & n.a. & n.a. \\
\hline $\begin{array}{l}\text { O’Brien } \\
1990 \text { [109] }\end{array}$ & $\begin{array}{l}2362 \text { patients } \\
\text { Risk medium } \\
\text { Prospective }\end{array}$ & $\begin{array}{l}5066 \text { polyps } \\
3371 \text { adenomas }\end{array}$ & - & - & - & & & \\
\hline $\begin{array}{l}\text { Weston } \\
1995[110]\end{array}$ & $\begin{array}{l}901 \text { patients } \\
\text { Risk unknown } \\
\text { Prospective }\end{array}$ & $\begin{array}{l}1938 \text { polyps } \leq 5 \mathrm{~mm} \\
920 \text { adenomas } \\
88 \text { adenomas mixed }\end{array}$ & 0.26 & n.a. & n.a. & 0 & n.a. & n.a. \\
\hline $\begin{array}{l}\text { Read } \\
1997[111]\end{array}$ & $\begin{array}{l}768 \text { patients ( } 311 \text { with } \\
\text { adenomas) } \\
\text { 1st sigmoidoscopy } \\
\text { Risk medium }\end{array}$ & 203 adenomas distal & 6 & 21 & 36 & - & - & - \\
\hline $\begin{array}{l}\text { Nusko } \\
1997[112]\end{array}$ & $\begin{array}{l}5621 \text { patients } \\
\text { Risk unknown }\end{array}$ & $\begin{array}{l}20076 \text { polyps } \\
11188 \text { adenomas }\end{array}$ & n.a. & - & n.a. & 0 & $\begin{array}{c}2.2(6- \\
15 \mathrm{~mm})\end{array}$ & n.a. \\
\hline $\begin{array}{l}\text { Aldridge } \\
2001[113)\end{array}$ & $\begin{array}{l}445 \text { patients } \\
\text { Risk unknown } \\
\text { Prospective }\end{array}$ & $\begin{array}{l}1228 \text { polyps } \\
657 \text { adenomas }\end{array}$ & 1.1 & 6.8 & 5.8 & 0 & 1.5 & 10.2 \\
\hline $\begin{array}{l}\text { Gschwantler } \\
2002[102]\end{array}$ & $\begin{array}{l}4216 \text { patients } \\
\text { Risk unknown } \\
\text { Retrospective }\end{array}$ & $\begin{array}{l}11283 \text { polyps } \\
9038 \text { adenomas } \\
3016 \text { adenomas }<5 \mathrm{~mm}\end{array}$ & - & - & - & - & - & - \\
\hline $\begin{array}{l}\text { Pickhardt } \\
2003[114]\end{array}$ & $\begin{array}{l}1233 \text { patients } \\
\text { Risk medium } \\
\text { Prospective }\end{array}$ & $\begin{array}{l}1310 \text { polyps } \\
554 \text { adenomas } \\
966 \text { polyps }<5 \mathrm{~mm} \\
344 \text { adenomas }<5 \mathrm{~mm}\end{array}$ & $\begin{array}{l}0.1 \\
0.3^{2}\end{array}$ & $\begin{array}{l}- \\
-\end{array}$ & - & $\begin{array}{l}0 \\
0\end{array}$ & $\begin{array}{l}0 \\
0\end{array}$ & $\begin{array}{l}2.4 \\
4.0^{2}\end{array}$ \\
\hline $\begin{array}{l}\text { Church } \\
2004 \text { [115] }\end{array}$ & $\begin{array}{l}5123 \text { patients } \\
\text { Risk increased } 27 \% \\
\text { Retrospective }\end{array}$ & $\begin{array}{l}2980 \text { adenomas } \\
5490 \text { polyps } \\
4381 \text { polyps } \leq 5 \mathrm{~mm}\end{array}$ & $\begin{array}{l}2.6^{2} \\
1.9\end{array}$ & $\begin{array}{c}12.9^{2} \\
3.6\end{array}$ & $\begin{array}{l}47.8^{2} \\
24.8\end{array}$ & $\begin{array}{l}0.05^{1,2} \\
-\end{array}$ & $\begin{array}{l}0.15^{1,2} \\
-\end{array}$ & $\begin{array}{l}4.2^{1,2} \\
-\end{array}$ \\
\hline $\begin{array}{l}\text { O’Brien } \\
2004 \text { [116] }\end{array}$ & $\begin{array}{l}938 \text { patients } \\
\text { Risk medium } \\
\text { Retrospective }\end{array}$ & 1750 adenomas & 0.7 & 6.5 & 15.5 & 0 & 0.4 & 0.8 \\
\hline $\begin{array}{l}\text { Souques } \\
2006 \text { [117] }\end{array}$ & $\begin{array}{l}10936 \text { patients } \\
\text { Risk medium } \\
\text { Retrospective }\end{array}$ & $\begin{array}{l}15458 \text { polyps } \\
9280 \text { adenomas } \\
8511 \text { polyps }<5 \mathrm{~mm} \\
4429 \text { adenomas }<5 \mathrm{~mm}\end{array}$ & $\begin{array}{l}12.9 \\
25.8^{2}\end{array}$ & $\begin{array}{l}26.6 \\
38.7^{2}\end{array}$ & $\begin{array}{l}87.7 \\
86.6^{2}\end{array}$ & - & - & - \\
\hline $\begin{array}{l}\text { Chen } \\
2006 \text { [118] }\end{array}$ & & $\begin{array}{l}4279(<6 \mathrm{~mm}) \\
753(6-9 \mathrm{~mm})\end{array}$ & 2.6 & 9.7 & - & - & & \\
\hline $\begin{array}{l}\text { Butterly } \\
2006[119]\end{array}$ & $\begin{array}{l}3291 \text { patients ( } 1235 \text { with } \\
\text { polyps) } \\
\text { Risk medium and increased } \\
\text { Retrospective }\end{array}$ & 1933 adenomas $\leq 10 \mathrm{~mm}$ & 2.6 & 7.8 & n.a. & 0.1 & 0.4 & n.a. \\
\hline $\begin{array}{l}\text { Kim } \\
2007[120]\end{array}$ & & $\begin{array}{l}2955 \text { polyps } \\
2006 \text { polyps }>5 \mathrm{~mm}\end{array}$ & 0.2 & 1.8 & & 0.08 & 2.0 & \\
\hline $\begin{array}{l}\text { Yoo } \\
2007[121]\end{array}$ & $\begin{array}{l}7006 \text { patients } \\
\text { Risk unknown }\end{array}$ & $\begin{array}{l}5996 \text { adenomas } \\
3303 \text { adenomas }<5 \text { mm }\end{array}$ & $0.15^{2}$ & $2.1^{2}$ & $15.2^{2}$ & $0^{2}$ & $0.5^{2}$ & $1.6^{2}$ \\
\hline $\begin{array}{l}\text { Lieberman } \\
2008[122]\end{array}$ & $\begin{array}{l}13609 \text { ( } 6360 \text { with polyps) } \\
\text { Risk medium } 64 \% \text { (FOBT } \\
14 \% \text { ) } \\
\text { Risk increased } 22 \% \\
\text { Retrospective }\end{array}$ & $\begin{array}{l}5977 \text { polyps } \\
3493 \text { adenomas } \\
1880 \text { adenomas }<5 \mathrm{~mm} \\
3764 \text { polyps }\end{array}$ & $\begin{array}{l}1.2^{3} \\
1.7^{3,4}\end{array}$ & $\begin{array}{l}5.1^{3} \\
6.4^{3,4}\end{array}$ & $\begin{array}{l}26.3^{3} \\
27.9^{3,4}\end{array}$ & $0^{3}$ & $0.2^{3}$ & $2.6^{3}$ \\
\hline $\begin{array}{l}\operatorname{Rex} \\
2009[123]\end{array}$ & $\begin{array}{l}10034 \text { ( } 5079 \text { with polyps) } \\
\text { Risk medium } 20 \% \text {, in- } \\
\text { creased } 31 \% \\
\text { Retrospective }\end{array}$ & $\begin{array}{l}10780 \text { polyps } \\
8798 \text { polyps }<5 \mathrm{~mm} \\
5084 \text { adenomas }\end{array}$ & 0.9 & 5.3 & - & 0.05 & 0 & - \\
\hline $\begin{array}{l}\text { Graser } \\
2009 \text { [124] }\end{array}$ & - & $\begin{array}{l}511 \text { polyps } \\
468 \text { polyps }<5 \mathrm{~mm}\end{array}$ & 1.7 & 10.7 & 51.4 & 0 & 0 & 2.7 \\
\hline $\begin{array}{l}\text { Bretagne } \\
2010[125]\end{array}$ & $\begin{array}{l}784 \text { patients } \\
\text { FOBT-positive } \\
\text { Retrospective }\end{array}$ & $\begin{array}{l}1284 \text { adenomas } \\
520 \text { adenomas }<5 \mathrm{~mm} \\
\text { adenomas }\end{array}$ & $2.8^{2}$ & $15.5^{2}$ & $46.8^{2}$ & $0.4^{2}$ & $0.5^{2}$ & $12.3^{2}$ \\
\hline
\end{tabular}




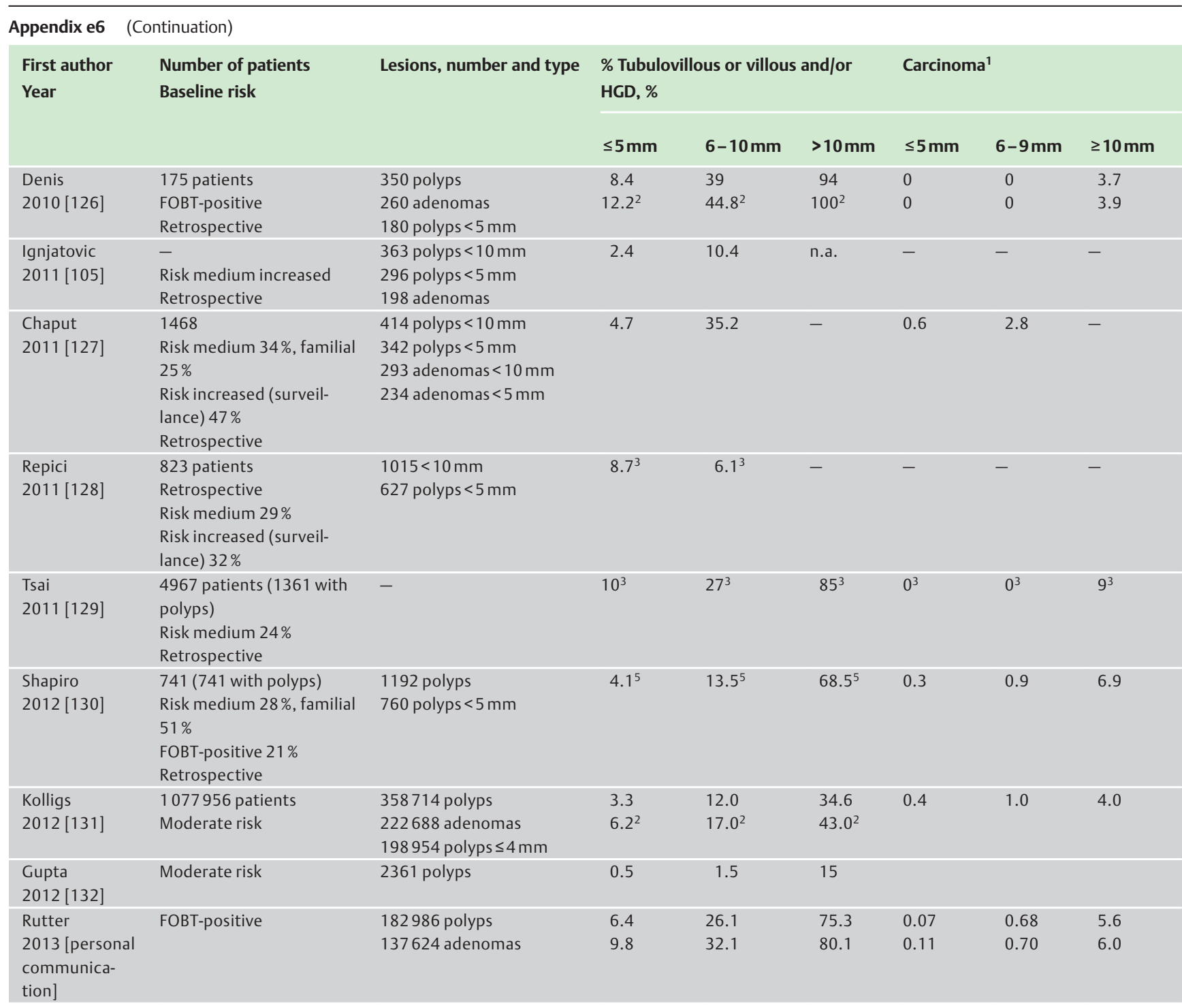

HGD, high grade dysplasia; n.a., not available; FOBT, fecal occult blood test;

1 carcinoma only

$2 \%$ expressed per adenoma

$3 \%$ expressed per patient

${ }^{4}$ including serrated adenomas

${ }^{5}$ tubulovillous or villous or high grade dysplasia or carcinoma 
Appendix e7 Interobserver agreement for characterization of polyps as neoplastic or non-neoplastic: kappa values for narrow band imaging (NBI), magnified NBI, i-SCAN, and autofluorescence imaging (AFI).

\begin{tabular}{|c|c|c|c|c|}
\hline Study authors, year & NBI & NBI magnified & i-SCAN & AFI \\
\hline Masci et al., 2012 [146] & & & 0.446 & \\
\hline Pigo et al., 2012 [147] & & & 0.462 & \\
\hline Ignjatovic et al., 2011 [104] & 0.48 & 0.63 & & 0.48 \\
\hline Ignjatovic et al., 2011 [121] & 0.85 & & & \\
\hline Raghavendra et al., 2011 [122] & 0.69 & & & \\
\hline Higashi et al., 2010 [124] & & 0.85 & & \\
\hline Van den Broek et al., 2009 [148] & 0.77 & & & 0.33 \\
\hline Rastogi et al., 2009 [149] & 0.63 & & & \\
\hline East et al., 2007 [151] & & 0.48 & & \\
\hline Sato et al., 2011 [152] & 0.54 & & & 0.54 \\
\hline
\end{tabular}


Appendix e8 Summary of evidence for the cost-effectiveness of a resect and discard policy.

\begin{tabular}{|c|c|c|c|c|c|c|}
\hline $\begin{array}{l}\text { Study authors, } \\
\text { year }\end{array}$ & Study design & Intervention & Participants & Outcomes & Results & Conclusions \\
\hline $\begin{array}{l}\text { Hassan et al., } \\
2010 \text { [167] }\end{array}$ & $\begin{array}{l}\text { Markov } \\
\text { modelling }\end{array}$ & $\begin{array}{l}\text { In vivo diagnosis, } \\
\text { NBI } \\
\text { Polyps < } 5 \mathrm{~mm} \text {, }\end{array}$ & $\begin{array}{l}\text { US screening } \\
\text { population }\end{array}$ & $\begin{array}{l}\text { Reduction in } \\
\text { screening costs }\end{array}$ & $\begin{array}{l}\text { Savings of } \$ 25 / \text { person, } \\
\text { without any meaningful ef- } \\
\text { fect on screening efficacy } \\
\text { US population undiscount- } \\
\text { ed annual savings of } \\
\$ 33 \text { million. } \\
\text { No effect on screening } \\
\text { efficacy }\end{array}$ & $\begin{array}{l}\text { Resect and discard } \\
\text { strategy for diminu- } \\
\text { tive polyps detected } \\
\text { by screening colo- } \\
\text { noscopy resulted in a } \\
\text { substantial econom- } \\
\text { ic benefit without an } \\
\text { impact on efficacy }\end{array}$ \\
\hline $\begin{array}{l}\text { Longcroft- } \\
\text { Wheaton et al., } \\
2011[166]\end{array}$ & $\begin{array}{l}\text { Prospective } \\
\text { cohort study }\end{array}$ & $\begin{array}{l}\text { In vivo diagnosis, } \\
\text { FICE and convention- } \\
\text { al chromoendoscopy } \\
\text { (indigo carmine) } \\
\text { with reference to PIVI } \\
\text { Polyps }<10 \mathrm{~mm}\end{array}$ & $\begin{array}{l}\text { UK bowel } \\
\text { cancer } \\
\text { screening } \\
\text { population }\end{array}$ & $\begin{array}{l}\text { Cost of histopatholo- } \\
\text { gical examination of } \\
\text { polyps }\end{array}$ & $\begin{array}{l}\text { Surveillance interval could } \\
\text { be set correctly in: } \\
\text { - } 97 \% \text { of cases, by BSG } \\
\text { guidelines, using FICE } \\
\text { or indigo carmine } \\
\text { chromoendoscopy } \\
\text { - } 97 \% \text { of cases, by ASGE } \\
\text { guidelines, using FICE } \\
\text { - 99\% of cases, by ASGE } \\
\text { guidelines, with indigo } \\
\text { carmine chromoen- } \\
\text { doscopy } \\
\text { A saving of } € 678253 \\
\text { (€762 } 767 \text { ) per annum } \\
\text { could be made within the } \\
\text { UK Bowel Cancer Screen- } \\
\text { ing Programme ( } £ 55 \\
\text { [€62] per person under- } \\
\text { going screening colonos- } \\
\text { copy) }\end{array}$ & $\begin{array}{l}\text { FICE and indigo car- } \\
\text { mine chromoendos- } \\
\text { copy can lead to sig- } \\
\text { nificant cost savings }\end{array}$ \\
\hline $\begin{array}{l}\text { Gupta et al., } \\
2012 \text { [165] }\end{array}$ & $\begin{array}{l}\text { Retrospective } \\
\text { multicenter } \\
\text { cohort study }\end{array}$ & $\begin{array}{l}\text { In vivo diagnoisis, } \\
\text { NBI with reference } \\
\text { to PIVI } \\
\text { Polyps }<5 \mathrm{~mm}\end{array}$ & $\begin{array}{l}\text { US screening } \\
\text { population }\end{array}$ & $\begin{array}{l}\text { Savings in histo- } \\
\text { pathology costs }\end{array}$ & $\begin{array}{l}\text { Total histopathology cost } \\
\text { of } 1254 \text { polyps, } \$ 133000 \\
\text { Total saving of } \$ 127000 \\
\text { possible ( } \$ 309[€ 210] \text { per } \\
\text { patient) }\end{array}$ & $\begin{array}{l}\text { Cost savings follow- } \\
\text { ing PIVI guideline } \\
\text { feasible }\end{array}$ \\
\hline $\begin{array}{l}\text { Ignjatovic et al., } \\
2009 \text { [103] }\end{array}$ & $\begin{array}{l}\text { Prospective } \\
\text { cohort study }\end{array}$ & $\begin{array}{l}\text { In vivo diagnosis, } \\
\text { NBI } \\
\text { Polyps }<10 \mathrm{~mm}\end{array}$ & $\begin{array}{l}\text { UK screening } \\
\text { population }\end{array}$ & $\begin{array}{l}\text { Savings in histo- } \\
\text { pathology costs }\end{array}$ & $\begin{array}{l}\text { Reduction in histopatho- } \\
\text { logy costs of } £ 6783 \\
\text { ( } \$ 11000) \\
\text { Overall saving of } £ 13353 \\
(\$ 22000) \text { or } 77 \% \text { for the } \\
\text { cohort of } 130 \text { patients ( } £ \\
102[€ 115 \text { ] per patient) }\end{array}$ & \\
\hline
\end{tabular}

NBI, narrow band imaging; FICE, Fujinon Intelligent Color Enhancement; PIVI, preservation and Incorporation of valuable endoscopic interventions [106]; BSG, British Society of Gastroenterology; ASGE, American Society for Gastrointestinal Endoscopy 